\title{
The utility of new data in understanding housing insecurity
}

Authored by

Maria B. Yanotti , University of Tasmania

Marcus Banks, RMIT University

Ashton de Silva, RMIT University

Nandini Anantharama, RMIT University

Peter Whiteford, Australian National University

Dina Bowman, The Brotherhood of St Laurence

Zsuzsanna Csereklyei, RMIT University
Publication Date March 2021

DOI 10.18408/ahuri5321801 
Title

The utility of new data in understanding housing insecurity

\section{Authors}

Maria B. Yanotti , University of Tasmania

Marcus Banks, RMIT University

Ashton de Silva, RMIT University

Nandini Anantharama, RMIT University

Peter Whiteford, Australian National University

Dina Bowman, The Brotherhood of St Laurence

Zsuzsanna Csereklyei, RMIT University

\section{ISBN}

978-1-922498-18-2

\section{Key words}

Within-year income volatility, Commonwealth Rent Assistance (CRA), housing stability, Commonwealth support payments.

\section{Series}

AHURI Final Report

\section{Number}

351

\section{ISSN}

1834-7223

\section{Publisher}

Australian Housing and Urban Research Institute Limited Melbourne, Australia

\section{DOI}

10.18408/ahuri5321801

\section{Format}

PDF, online only

URL

\section{https://www.ahuri.edu.au/research/final-reports/351}

\section{Recommended citation}

Yanotti, M., Banks, M., de Silva, A., Anantharama, N., Whiteford, P., Bowman, D. and Csereklyei, Z. (2021) The utility of new data in understanding housing insecurity, AHURI Final Report No. 351, Australian Housing and Urban Research Institute Limited, Melbourne, https://www.ahuri.edu.au/research/ final-reports/351, doi: 10.18408/ahuri5321801.

\section{AHURI}

AHURI is a national independent research network with an expert not-for-profit research management company, AHURI Limited, at its centre.

AHURI's mission is to deliver high quality research that influences policy development and practice change to improve the housing and urban environments of all Australians.

Using high quality, independent evidence and through active, managed engagement, AHURI works to inform the policies and practices of governments and the housing and urban development industries, and stimulate debate in the broader Australian community.

AHURI undertakes evidence-based policy development on a range of priority policy topics that are of interest to our audience groups, including housing and labour markets, urban growth and renewal, planning and infrastructure development, housing supply and affordability, homelessness, economic productivity, and social cohesion and wellbeing.

\section{Acknowledgements}

This material was produced with funding from the Australian Government and state and territory governments. AHURI Limited gratefully acknowledges the financial and other support it has received from these governments, without which this work would not have been possible.

AHURI Limited also gratefully acknowledges the contributions, both financial and in-kind, of its university research partners who have helped make the completion of this material possible.

\section{Disclaimer}

The opinions in this report reflect the views of the authors and do not necessarily reflect those of AHURI Limited, its Board, its funding organisations or Inquiry Panel members. No responsibility is accepted by AHURI Limited, its Board or funders for the accuracy or omission of any statement, opinion, advice or information in this publication.

\section{AHURI journal}

AHURI Final Report journal series is a refereed series presenting the results of original research to a diverse readership of policy makers, researchers and practitioners.

\section{Peer review statement}

An objective assessment of reports published in the AHURI journal series by carefully selected experts in the field ensures that material published is of the highest quality. The AHURI journal series employs a double-blind peer review of the full report, where anonymity is strictly observed between authors and referees.

\section{Copyright}

(C) Australian Housing and Urban Research Institute Limited 2021

This work is licensed under a Creative Commons Attribution-NonCommercial 4.0 International License, see http://creativecommons.org/licenses/by-nc/4.0/. 


\section{Contents}

Acronyms and abbreviations used in this report

List of tables

List of figures

Executive summary 1

1. Towards a more dynamic understanding of CRA 5

1.1 Why was this exploratory project conducted? 7

1.2 Income volatility and housing instability 9

1.3 Commonwealth Rent Assistance and housing instability/affordability

1.4 Current understandings of the scope and scale of CRA receipt

1.5 Research questions

2. Within- and across-year patterns of CRA receipt: initial data insights

2.1 Data and methods

2.1.1 Data 18

2.1.2 Methods 19

2.2 Initial findings 21

2.2.1 CRA records 21

2.2.2 CRA recipients 23

2.2.3 The scale and scope of one-off CRA payments 28

2.2.4 Cohort 1 analysis 29

2.2.5 Insight: CRA receipt in 2016 40

3. Discussion and conclusions 42

References

Appendix 1: Working with the DOMINO

database-Insights 47

Appendix 2: Data requested 49

\section{Acronyms and abbreviations used in this report}

ABS Australian Bureau of Statistics

AHURI Australian Housing and Urban Research Institute Limited

AlHW Australian Institute of Health and Welfare

ATO Australian Taxation Office

CPI Consumer Price Index

CRA Commonwealth Rent Assistance

DOMINO Data Over Multiple Individual Occurrences

DSS Department of Social Services

FTB Family Tax Benefit

HILDA Household Income and Labour Dynamics in Australia

NSA Newstart Allowance 


\section{List of tables}

Table 1: Share of families with an income disruption over a year

Table 2: Structure and rates of rent assistance, people without dependent children, June 2020 (fortnightly figures)

Table 3: Structure and rates of rent assistance, people with dependent children, June 2020 (fortnightly figures)

Table 4: Fortnightly rent and CRA by primary payment type, December 2019

Table 5: Research questions

Table 6: Variables in focus 19

Table 7: CRA variables in focus

Table 8: CRA records by cohort

Table 9: CRA payment records by payment type (all records)

Table 10: CRA payment records associated with recipients' characteristics

Table 11: CRA and housing 23

Table 12: Number of people receiving selected

payments $2000-2017$ 24

Table 13: CRA recipients by cohort 24

Table 14: Last CRA spell 25

Table 15: Most common CRA spell $\quad 25$

Table 16: Most recent CRA payment duration $\quad 26$

Table 17: Most recent CRA spell by income support payment type

Table 18: Most common CRA spell by payment type 27

Table 19: CRA regular payment (daily rate) and one-off payments received (nominal dollars) 29

Table 20: Last spell and CRA type for Cohort 1 30

Table 21: Most recent and common CRA spells and weekly rent paid 37

Table 22: Sax Institute costs (November 2019) 48

Table 23: DOMINO variables requested 49

\section{List of figures}

Figure 1: Histogram of total accrued CRA payments by years

Figure 2: Number of people (Cohort 1) receiving CRA per year (accumulated) 30

Figure 3: Spell duration by last spell (Cohort 1) 31

Figure 4: Spell duration by most common spell (cohort 1)

Figure 5: CRA payment type by last spell (Cohort 1) 32

Figure 6: CRA payment type by most common spell (Cohort 1)

Figure 7: Age distribution of CRA at start date and end date, by number of payments spells (Cohort 1)

Figure 8: Proportion of CRA recipients by last spell and gender (Cohort 1)

Figure 9: Proportion of CRA recipients by most common spell and gender (Cohort 1)

Figure 10: CRA recipients by most recent spell across states (Cohort 1)

Figure 11: CRA recipients by most common spell across states (Cohort 1)

Figure 12: Proportion of CRA recipients by housing accommodation type by last spell (Cohort 1)

Figure 13: Proportion of CRA recipients by housing accommodation type by most common spell (Cohort 1)

Figure 14: Weekly rent distribution by last spell (Cohort 1)

Figure 15: Weekly rent distribution by most common spell (Cohort 1).

Figure 16: Regular CRA payment amount (daily rate) by last spell (Cohort 1)

Figure 17: Regular CRA payment (daily rate) by most common spell (Cohort 1).

Figure 18: Total one-off payment amount by last spell (Cohort 1)

Figure 19: Total one-off payment amount by most common spell (Cohort 1)

Figure 20: Diagram of operational model for researcher accessing SURE for two studies 


\section{Executive summary}

\section{Key points}

- This exploratory data project investigates the potential of the DSS DOMINO dataset to support housing research and policy development.

- The key difference is that DOMINO is mainly comprised of flow data which gives within year income volatility data rather than stock data which gives a single annual, or point-in-time income and labour force status data.

- Demand for Commonwealth Rental Assistance (CRA) is far higher than commonly understood and there is a significant churn of individuals who receive CRA.

\section{Key findings}

- Between January 2000 and October 2017, 11 million Australians were identified to have received a Centrelink payment. This finding offers compelling evidence that welfare is as much part of mainstream life as health and education.

- Over five million individuals received CRA during this period.

- Demand for CRA is far higher than commonly understood. We identified nearly two million $(1,967,028)$ income units who received CRA payments during 2016.

- There is a significant churn of individuals who receive CRA that is not captured by stock data commonly used in housing policy analyses. We found a highly fluid population relied on CRA during 2016, with 747,167 income units starting to receive this payment and 505,942 ceasing receipt.

- CRA recipients received on average 3.2 instances of CRA payments; half of them receiving 2 instances of CRA payments during the period studied.

- 70 per cent of those who received CRA between January 2000 and October 2017 received less than three years total accrued CRA payments.

- The most recent CRA benefit spell experienced by a recipient was quite short-51 per cent of recipients most recently received this payment for less than a year. Over a quarter only received CRA payments for under 120 days, suggesting within-year income volatility. 
- Most CRA recipients appear to have received at least one one-off irregular CRA payment, suggesting withinyear income volatility.

- Overall, women are more likely than men to receive CRA, and were more likely than men to have (most recently and commonly) received CRA for spells of more than 270 days.

- Conversely, men are more likely than women to have (most recently and commonly) received a short spell of CRA (less than 270 days).

- Newstart recipients were far more likely to have most recently (77\%) received a spell of CRA shorter than a year-reflecting the policy design of this payment. In contrast 72.6 per cent of the most recent CRA spells linked to FTB payments were for more than a year-reflecting the longer term needs of families with dependent children.

- While the number of people receiving CRA payments per year has increased over time, there are fewer new CRA recipients joining every year.

\section{Technical findings}

A deeper understanding of the database's complex variables and values-and their historically- and policyinscribed relationships -is required for more detailed research.

- Once these issues are resolved, DOMINO offers a unique and powerful resource for housing and welfare research. Regressions, time-series analyses and other modelling techniques are likely to yield important findings for a wide range of academic disciplines.

- We strongly encourage pursuit of further studies utilising this rich information source.

- We note that successful investigations will demand significant resources in terms of personnel and labour as well as liberal timelines, unlike studies typically undertaken in our field. In particular, teams comprising domain experts in welfare, public policy and econometrics/statistics are necessary.

- Our main finding is that we have shown that receiving CRA is a more common experience than is generally thought, and further, that flow data analyses can reveal both the diversity of engagements Australians have with the social security system and their distinctive patterns.

In Australia's predominately private rental market, Commonwealth Rent Assistance (CRA) is an important social security payment designed to assist low-income households with rental costs. This project explores the potential of a novel dataset to yield new insights into patterns of CRA receipt in households reliant on Newstart Allowance (NSA), pensions and Family Tax Benefit (FTB).

In the month prior to the onset of the COVID-19 crisis, DSS data extracted on 27 December 2019 showed that CRA was being paid to nearly 1.3 million income units (individuals or couples) living in rental accommodation (DSS 2019). Significant proportions of those in receipt of Newstart Allowance (38\%) and Parenting Payment Single (PPS) (53\%) relied on receiving CRA at this time.

UN Secretary General António Guterres has warned that the current coronavirus outbreak is the biggest global challenge since World War Two (BBC 2020). There are mounting fears that the world will experience a lengthy recession of a depth not witnessed since the Great Depression of the 1930s (New York Times 2020).

In Australia, government policy interventions to support the rental and mortgage sectors were swift. Measures introduced include: income assistance, such as a temporary doubling of the JobSeeker payment; the JobKeeper labour market retention initiative; a moratorium on evictions and rent increases; land tax relief; direct financial assistance to tenants in hardship; encouraging mediation between tenants (commercial and residential) and landlords; and landlords deferring or renegotiating mortgage payments with their financial institutions (AHURI 2020). 
As the pandemic subsides, the reverse is happening with unemployment and underemployment-related payments such as JobSeeker Allowance (Newstart) and Parenting Payment. In its August Statement on Monetary Policy, the Reserve Bank of Australia forecasted unemployment to peak at over 10 per cent in December 2020 and remain at over 7 per cent for up to two years (RBA 2020). CRA payments will reflect this unparalleled increase in income support payments.

Developing nuanced and effective housing policy responses to the pandemic's impact requires a firm understanding of the potential demand for CRA - the likely scale, scope and prevalence of households' needs for rent assistance. One key aspect of meeting those needs is for an adequate, fast, reliable and steady rental support payment when required.

\section{Income volatility}

International studies suggest that low-income households with volatile incomes face sharply higher risks of housing instability (McKernan, Ratcliffe et al. 2016; Smith-Ramani, Mitchell et al. 2017). To date, however, Australian housing policies, programs and practices lack an evidence-based understanding of how erratic incomes may weaken housing affordability, destabilise tenure, ${ }^{1}$ and undermine household financial risk management strategies.

From a housing and broader public policy perspective, a robust understanding of the impact that income volatility may have on households should be actively sought. International studies have found that households whose incomes fluctuate by more than 25 per cent from pay to pay experience sharply higher risks of emotional conflict (Hill, Morris et al. 2013), housing instability (Smith-Ramani, Mitchell et al. 2017) and financial hardship (Hacker, Huber et al. 2012; Morris, Hill et al. 2015; Nichols and Rehm 2014).

\section{Stock and flow data}

Australian housing research commonly relies on datasets offering stock data-annual or point-in-time income and labour force status data. Most HILDA, ATO and Household Expenditure Survey/Survey of Income and Housing stock and survey data, however, do not capture within-year income heterogeneity. Statistical investigations into questions of household financial risks in labour, housing and welfare markets therefore confront the potentially significant problem of aggregation bias.

This is the first academic study of 'flow data' from a newly available DSS dataset to assist investigations of withinyear income volatility in Australia. The unit-record data in DOMINO is primarily comprised of events-each a record of a change that occurred in an individual's circumstances that day which may affect their social security payment eligibility, rate or payability. ${ }^{2}$ This very large, highly complex dataset includes, at an individual and household level, daily event-based information on all Australian social security recipients' demographics, benefits history, concessions, and housing since the year 2000.

There are a wide range of circumstances where an event is recorded, ranging from changes in household composition and address; adjustments in rates due to the Department's assets and income tests; application of the activity test; compliance with administrative procedures; and transfers to another payment. The period between an event recorded on one day and the next event is therefore not fixed.

As an initial step to explore the potential relationship between income volatility and housing instability, this research examines the individual within-year and across-year patterns of CRA receipt.

1 Households suffer from housing instability and insecurity when they live in housing that is unaffordable and does not adequately meet their need for safety, considering the quality of the housing stock and its location. Housing stability is the extent to which an individual's customary access to housing of reasonable quality is secure (Frederick, Chwalek et al. 2014). Housing instability can be reflected by frequent moving, staying with family and friends, and/or experiencing homelessness.

2 For a definition of payability see Social Security Guide, 3.1.6.10 General payability provisions, https://guides.dss.gov.au/guide-socialsecurity-law/3/1/6/10. 
In statistical terms, we investigated the CRA population using flow data, rather than stock data. Official statistics of people receiving income support payments (through which the CRA supplement is paid) use stock data. For example, the quarterly and annual DSS reports count the number of recipients on one day close to the end of the quarter ${ }^{3}$ or year. ${ }^{4}$ There is also a monthly report that counts the number of recipients on each Friday of the month to arrive at an average figure. ${ }^{5}$ These types of stock data, however, do not count the total number of individuals who received an income support payment over the period of a month, quarter or year. Our exploratory study of flow counts moves beyond this limitation.

The results from this project aim to contribute within-year insights into the financial experience of households receiving CRA and showcase DOMINO as a potentially rich resource for AHURI research. This pioneering study offers policy makers and researchers a more nuanced appreciation of a potential housing tenure risk facing some of our most vulnerable households and individuals - the timely receipt and adequacy of CRA and of primary income support payments.

Overall, these initial findings from this study of a sample of the database illustrate DOMINO's potential for actionable research. Our insights are conditional and based only on data provided by DSS. Other data not requested by the research team may alter these provisional findings.

3 DSS Payment Demographic Data available at: https://data.gov.au/data/dataset/dss-payment-demographic-data.

4 DSS Payment Trends and Profile Reports. Available at https://data.gov.au/dataset/ds-dga-4ccff587-4a46-4ab9-8833-76dadaa10ebe/ details?q=DSS.

5 https://www.dss.gov.au/labour-market-and-related-payments-march-2016-labour-market-and-related-payments-may-2018-labourmarket-and-related-payments-november-2019/labour-market-and-related-payments-february-2020. 


\section{Towards a more dynamic understanding of CRA}

- Housing research supporting improvements in Australian housing policy, program development and delivery is often empirically informed by annual or point-in-time income data, which does not capture the amount of income households received each fortnight or how it may fluctuate.

- A volatile income significantly increases a household's financial and emotional risks.

- Income volatility occurs in real time, from pay period to pay period.

- Methodological limitations of using stock and survey data include the inability to capture the within-year 'spells' of households occupying unaffordable housing, the relationship between household cash-flow risks and housing insecurity, and the underemployment persistence and intensity over time and its effect on housing insecurity.

- Statistical investigations into questions of household financial risks in labour, housing and welfare markets confront a potentially significant obstacle of aggregation bias.

- Emerging research finds that it is false to assume a person's annual income is closely correlated to the actual income received on a particular month.

- From a housing and broader public policy perspective, a robust understanding of the impact income volatility may have on households should be actively sought.

- Within-year household income variation in Australia is very likely to have distinctive rhythms and patterns due to specific local labour market and welfare systems. 
- It is untested whether Australia's highly targeted and more responsive welfare system may lessen the level of household income volatility, compared to that found in the US, or whether Australia's higher rates of casual work and underemployment may heighten income variation compared to the UK and the US.

- As an initial step to investigate the potential relationship between income volatility and housing instability, this exploratory research examines the within-year receipt CRA, exploring the capability of the newly-available DOMINO dataset to explore within-year income heterogeneity.

- Changes in CRA may reflect the volatility of household incomes or other circumstances that can be associated with housing stress. 


\subsection{Why was this exploratory project conducted?}

This exploratory data project examines patterns of Commonwealth Rental Assistance (CRA) receipt in households reliant on Newstart Allowance (NSA), pensions and Family Tax Benefit. In Australia's predominately private rental market, CRA is a core social security payment designed to financially assist low-income households to maintain their tenancies.

Research supporting improvements in Australian housing policy, program development and delivery is often empirically informed by annual or point-in-time income and labour force engagement data. For example, DSS stock data extracted on 27 December 2019 showed that CRA was being paid to nearly 1.3 million income units (individuals or couples) living in rental accommodation (DSS 2020). Significant proportions of those in receipt of Newstart Allowance (38\%) and Parenting Payment Single (53\%) relied on receiving CRA on that date. However, using such data restricts analyses as it does not capture the total flow of CRA recipients during a period of time, nor their patterns of receipt.

Australian studies of housing affordability, insecurity or access have identified the methodological limitations of using stock and survey data. For example:

- Across-year HILDA data does not capture the within-year 'spells' of households occupying (un-)affordable housing (Wood, Ong et al. 2015: 16)

- Relevant data to investigate the relationship between household cash-flow risks and housing insecurity is absent in Census and other large datasets (Stone, Sharam et al. 2015: 82)

- Aggregate Census data cannot be used to unpack the distance-to-work, housing cost and dwelling size compromises made by specific households (van den Nouwelant, Crommelin et al. 2016: 2)

- Data to measure the relationship between underemployment and housing insecurity is problematic, as available datasets lack the resources to measure underemployment persistence and intensity over time (Campbell, Parkinson et al. 2014: 86)

Current research informing housing policy is hampered by the fact that HILDA, ATO and ABS survey data do not capture the amount of income households received each fortnight or how it may fluctuate. A new initiative by the Australian Government requiring employers with more than 20 staff to notify the Australian Taxation Office (ATO) of wages paid each pay period may go some way to dealing with this problem. ${ }^{6}$

One consequence of this gap is that statistical investigations into household financial risks in labour, housing and welfare markets confront a potentially significant obstacle of aggregation bias.

Research on the relationship between within-year income volatility and housing instability is largely based on the vast literature on income volatility across years. While existing research has documented a significant rise in income volatility for several countries since the 1970s (Dynan, Elmendorf et al. 2012; Hardy and Ziliak 2014; Jansen 2004) there is not much evidence of year-to-year income volatility for Australia. Li, La et al. (2020) explore the year-on-year changes in Australian income distribution over 15 years and identify fluctuations in market income (job losses and wage and non-wage cuts) to be the main driving change in income inequality.

6 The 2019-20 Federal Budget introduced 'Changing the Social Security Income Assessment Model', and 'Single Touch Payroll' expansion. This involves the 'real-time' transmission of earnings data from employers to the Department of Human Services. From 1 July 2020, income support recipients who are employed will report income received during the fortnight, with income data being shared with the Department of Human Services through expanded data-sharing arrangements. That is, earnings assessed will change from what is earned-what the employer is due to pay - to the earnings actually received. This measure will reduce the likelihood of income support recipients being overpaid income support payments (and subsequently being required to repay the amounts). The ATO is facilitating the expansion of this reporting to all employers with fewer than 20 employees by 2023 . However, social security recipients can be affected by changes in circumstances other than changes in earnings, and there may be challenges associated with multiple earner households. 
Understanding annual changes in income and wealth inequality is important. But, from a household-level perspective, there is a major limitation. There is a third inequality that has received far less attention: inequality in access to steady, predictable cash flows. As Morduch and Schneider (2016) explain:

\begin{abstract}
When we think of income, we think in terms of annual totals. When we think about wealth, we think about year-end account balances. Yet what keeps many people up at night are the ups and downs of their finances within the year-and whether or not they will have cash on hand to pay next week's bills. While we all know that income and expenses can fluctuate from month to month, we tend to assume that the variability is negligible or at least predictable-a five-week month or a tax refund or the holidays, for instance.
\end{abstract}

From a household-level perspective, the term 'income volatility' should not only refer to variability in annual data for analysis. Emerging research from the US finds that it is false to assume a person's annual income is closely correlated to the actual income she or he may receive on a particular month. A JPMorgan Chase study of 1 million randomly selected bank customers found that a majority (55\%) experienced month-to-month income fluctuations of more than 30 per cent, with labour market earnings the major contributor for this volatility (Farrell and Greig 2016: 9). Similarly, the internationally respected US Financial Diaries study tracking a small sample of low- and moderate-income households noted an average coefficient of variation of monthly income (within year, averaged across households) of 39 per cent (Hannagan and Morduch 2015). ${ }^{7}$

The sparser literature in the UK is inconclusive-with some panel data studies finding income instability increasing (Bartels and Bönke 2013; Daly and Valletta 2008) while others discern a flat or declining trend (Avram, Brewer et al. 2018; Jenkins and Cappellari 2014).

A recent report by a think tank, the Resolution Foundation-Irregular Payments: Assessing the breadth and depth of month to month earnings volatility - was based on anonymised transaction data from over seven million Lloyds Banking Group accounts (Tomlinson 2018). The study found that monthly pay fluctuations are the norm for the majority of employees, with only 9 per cent of employees who remained with the same employer throughout 2016-17 having no months in which take-home pay changed by greater than five per cent, either up or down. Over 80 per cent of lower earners (those with annual take-home pay of around $£ 10,000$ a year) with a steady job had volatile pay, compared to two-thirds of those on higher earnings (with take-home pay of around £35,000 a year). The absolute average monthly pay change for those with a steady job was highest for those on the very lowest earnings (in excess of 15 per cent),

The prevalence and persistence of within-year household income variation in Australia has been barely explored. A qualitative study of 70 low- and moderate-income households recently conducted by two researchers on the project team found that over half the participants had highly erratic (>25\%) fortnightly incomes (Banks and Bowman 2017; Bowman and Banks 2018). Further, among households with similar annual incomes, participants managing volatile incomes had lower levels of financial confidence and were less likely to hold household contents insurance.

From a housing and broader public policy perspective, a robust understanding of the impact income volatility may have on households should be actively sought. International studies have found that households whose incomes fluctuate by more than 25 per cent from pay to pay experience sharply higher risks of emotional conflict (Hill, Morris et al. 2013), housing instability (Smith-Ramani, Mitchell et al. 2017) and financial hardship (Hacker, Huber et al. 2012; Morris, Hill et al. 2015; Nichols and Rehm 2014).

7 The coefficient of variation is the most common measure of income volatility over time. The CV is the standard deviation of a household's monthly income over time expressed as a percentage of the household's average monthly income during that same period. 
Within-year household income variation in Australia is likely to have distinctive rhythms and patterns due to specific local labour market and welfare systems (Banks and Bowman 2019). In contrast to the prevalence of monthly wages and welfare payments in the UK and the US, the bulk of the employed labour force in Australia is paid fortnightly (61\%) or weekly (21\%) (Australian Payroll Association 2019: 4). Similarly, nearly all Australian social security pensions, payments and allowances are paid fortnightly to over five million individuals (DSS 2020).

In 2018 around one quarter of all employees had pay that varied from one pay period to the next (excluding overtime); for casual workers (those without paid leave), the share was 51 per cent. Around 38 per cent of casual employees and 21 per cent of all employees did not usually work the same hours each week (Australian Bureau of Statistics 2019). However, it is not known how great these variations in pay or hours are. Around 20 per cent of people receiving unemployment payments in 2019 were in part-time work (DSS 2019). At any point in time, individuals combining income support and part-time work constitute about 12 per cent of all part-time workers in Australia (Whiteford and Heron 2018). It is likely that those combining income support and part-time work are casual workers, experiencing higher rates of income volatility.

It is uncertain whether Australia's highly targeted and more responsive welfare system (Whiteford and Heron 2018) may lessen the level of household income volatility compared to that found in the US. Equally unclear is whether Australia's greater rates of casual work and time-related underemployment may heighten income variation compared to the UK and the US (ILO 2018).

As an initial step to investigate the potential relationship between income volatility and housing instability, this exploratory research examines the within-year receipt of CRA. A core contribution of this project is to pioneer using the newly-available DOMINO dataset to partially break through one of these methodological limitationsthe black box of within-year income heterogeneity. While a time-series analysis of the data was beyond the scope of this research, the initial within-year insights offered suggest the dataset has the potential for such an analysis.

\subsection{Income volatility and housing instability}

There has been sparse research on the relationship between income volatility and housing instability. A US study by McKernan, Ratcliffe et. al. (2016) investigated the relationship between family financial insecurity and four outcomes: eviction, ability to pay rent or mortgage, ability to pay utility bills, and reliance on public benefits. The authors applied three income disruption measures: involuntary job loss, a health-related work limitation, and an income drop of 50 per cent or more. They found that a quarter of households experienced at least one of these income disruptions over a year (Table 1-see notes for definitions).

Table 1: Share of families with an income disruption over a year

\begin{tabular}{lr}
\hline & Share of families \\
\cline { 2 - 2 } Income disruption & $\%$ \\
\hline Involuntary job loss & 6.2 \\
\hline Health-related work limitation & 5.1 \\
\hline Income drop of 50 percent or more & 17.6 \\
\hline Any of three disruptions & 25.7 \\
\hline
\end{tabular}

Source: Authors' tabulations of the 2008 Survey of Income and Program Participation, waves 11 through 13 (January-December 2012 ). ${ }^{8}$

8 Notes: Data are weighted using SIPP cross-sectional household weights. Involuntary job loss means the household head or spouse lost a job involuntarily for any length of time during the previous 12 months. Health-related work limitation means the household head or spouse experienced the onset of a health-related work limitation (of any length) during the previous 12 months. Income drop is a $50 \%$ or more decline in average family income between any given 4-month period over the previous 12 months. 
The impact of income disruption on housing stability was acute. Families who experienced an income drop of 50 per cent or more, a health-related work limitation or a job loss were about twice as likely to miss housing and utility payments than households who did not have these income disruptions. Among households experiencing an income drop of 50 per cent or more, 13.3 per cent missed a housing payment-compared to 7.2 per cent of families with steadier incomes.

Similarly, the proportion of households with unstable incomes who missed paying a utility bill (15\%) was significantly higher than more stable-income households (9.7\%). Among families who lost a job, 15.8 per cent missed a housing payment, compared to 7.3 per cent of households who did not experience a job loss. Evictions happened infrequently, but families who experienced an involuntary job loss were still more likely to be evicted (1.1\%) than families who did not (0.4\%).

Income instability also generates significantly higher housing risks in low-income families. Among families experiencing an income disruption, 18.9 per cent of low-income households missed a housing payment, compared to 12.4 per cent of middle-income families and 8.1 per cent of high-income households (McKernan, Ratcliffe et al. 2016: 12).

A report of income volatility research by Smith-Ramani and colleagues (2017) found a similar relationship with housing instability. The authors explain how housing instability has major policy ramifications:

\begin{abstract}
For example, households experiencing income volatility are more likely to be evicted, which can lead to greater municipal spending on housing assistance, homelessness prevention and rehousing, and other anti-poverty programs. Property tax revenue can dip if too many homeowners or landlords struggle to make mortgage payments. Cities with publicly owned utilities could also take a financial hit when their citizens miss payments, as Detroit did in 2014. The city faced national outrage over its decision to shut off thousands of mostly low-income households' water in an attempt to collect more than $\$ 90$ million in unpaid utilities bills. Given the percentage of Americans who are experiencing volatility, no community is immune (Smith-Ramani, Mitchell et al. 2017: 5).
\end{abstract}

\title{
1.3 Commonwealth Rent Assistance and housing instability/affordability
}

CRA provides a fortnightly non-taxable payment to low-income earners who rent privately. It is paid to private tenants as a supplement to other income support payments, and is subject to both individual and parental means tests (for some youth and student payments). CRA has been promoted as a more efficient means of providing housing support compared to public housing, as it decreases government expenditure and, theoretically, offers choice, flexibility and market responsiveness to recipients (Burke et al 2004). State and territory housing agencies also provide some additional support such as bond assistance to eligible individuals.

Australian research has explored the effect of CRA as a housing assistance program in several aspects of life such as housing affordability and accessibility, employment outcomes, age cohort effect, and regionality. Most of these studies rely on survey data-ABS Census, HILDA data or primary data from designed surveys. When assessing housing stress and affordability issues most studies looking at the effect of CRA use affordability measures such as rent-to-income ratio and income after housing costs.

In an early AHURI report, Hulse (2002: 40) argued that CRA as an income support offers 'no specific guarantees in terms of affordability benchmarks or the quality and suitability of housing' when reviewing housing allowances across liberal welfare regimes (including the US, Canada, Australia and New Zealand). More recent studies confirm that Australian benchmarks are yet to be developed. Parkinson, James et al. (2018: 20), for example, comment that with declines in private rental affordability relative to incomes, more income units have become eligible to receive the maximum rate of CRA-up from 75 per cent in June 2012 to 79.4 per cent in June 2016. While arguing CRA makes 'an important difference in alleviating housing affordability stress for many renters' they note that 41.2 per cent of private renters in June 2016 were in housing they could not afford or paying more than 30 per cent of their total income on rent. 
One reason for the low rate of CRA is because the supplement is indexed to the Consumer Price Index (CPI) rather than the rate of rental increase. A Productivity Commission (2017) report recognised that CRA has not kept pace with rent increases, recommending a 15 per cent increase in the supplement. However, like Hulse's argument made 15 years earlier, Parkinson, James et al. (2018: 78-79) point out 'this is an arbitrary number and does not relate to any benchmark or budget standard measure of affordability'.

The increasing pressures on rental affordability are becoming more widespread. More than one million low-income households (2.65 million people) rented in the private market in 2018, a figure that has more than doubled over the past two decades (Productivity Commission 2019). Household types including a person with a long-term health condition, disability or impairment; single parent households; households with at least one person aged 65 years or over; households including at least one unemployed person, and those including someone of Aboriginal or Torres Strait Islander origin were all also renting at higher rates in 2018 compared to 1994 (Productivity Commission 2019: 52). In their study of housing affordability,

Stone, Parkinson et al. (2016: 43-59) identified a similar range of households most vulnerable to housing affordability stress. They found overwhelming evidence that large proportions of households with a member receiving an Income Support Payment (including the Age Pension), Indigenous households, and younger people living alone faced housing-related financial strain.

A simulation model developed by Rowley, Leishman et al. (2017: 3) estimates that there are around 140,000 households unable to access private market housing in NSW (requiring support through subsidised tenures such as public and community housing) and a further 233,000 households requiring rent assistance to alleviate a position of rental stress. Equivalent figures are 110,000 and 181,000 in Victoria; 150,000 and 232,000 in Queensland; 59,000 and 73,000 in WA; and 14,000 and 17,000 in Tasmania. Overall, the model predicts that a large majority $(756,600)$ of households receiving CRA in 2019 would need to receive this payment to avoid rental stress (Table 3 , p. 35). However, despite receiving CRA, a substantial number of households continue to experience affordability stress over a prolonged period of time (Parkinson, James et al. 2018).

In their AHURI report on housing tenure, mobility and labour market behaviour, Whelan and Parkinson (2017: 11) make the important point that:

CRA offers substantially more flexibility than other forms of housing assistance, in that it is not location specific, but rather follows the household-an important policy mechanism for providing households with greater choices of where to locate. This is perceived as a major advantage over other forms of housing assistance, such as social or public housing, which may be lost if a household is geographically mobile.

AHURI research has also analysed the relationship between housing policies and labour force participation, concluding that CRA is well designed (due to the income test that withdraws CRA after basic benefits are exhausted) and that neither changes to CRA or to public housing eligibility and income tests are likely to have a significant impact on employment participation (Ong, Wood et al. 2017; Cigdem-Bayram, Ong et al. 2017). A recent Productivity Commission report (2019) also considers CRA to be well targeted to those who need the most assistance. Feeny, Ong et al. (2012) find that housing assistance status has little impact on employment outcomes. These studies have focused on the effects of the design of housing assistance on employment participation and on wellbeing outcomes (Parkinson, Cigdem et al. 2013).

Pending additions to the DOMINO data will potentially facilitate analysis of the effects of different forms and patterns of employment participation on housing choices and outcomes, thus complementing and extending previous research. ${ }^{9}$ The DOMINO data are also capable of tracking changes in tenure as well as changes in patterns of work, rather than simply identifying relationships at a point in time, and they also provide data that can be compared at different stages of the life cycle.

9 The AlHW has advised that DSS will include employment-related data in DOMINO in the near future. 
Importantly, CRA is part of the income support system, and aims to provide adequate income support. Individuals who face highly irregular income spells may rely on CRA payments to access and maintain housing. For example, Randolph and Holloway (2007) study low income households in the private rental market and their housing opportunities. However, their definition of low-income households is based on weekly Census income thresholds; which they complement with Centrelink data for the number of CRA recipients and the average CRA payment by postcode. This definition of low income could potentially underestimate the number of households experiencing affordability stress due to irregular income spells. The DOMINO data will allow us to explore the situation the CRA household recipients are in, and how prevalent the issue is across regions and household types.

Interestingly, Lawson, Pawson et al. (2018) found that over a twenty-year period, a funding model where government provides most of the capital to build/acquire social housing and doesn't pay CRA to tenants, and where community housing providers (CHPs) only have to borrow a very small amount of capital at lower interest rates (using the NHFIC bond aggregator) has the lowest overall costs to government. As government pays a greater capital subsidy when the dwelling is acquired/built it doesn't need to pay CRA over the long term, thereby reducing the overall costs. This model equates to an annual government subsidy of $\$ 9$ billion (to build, maintain and manage 727,300 additional social dwellings over 20 years), while a model relying on CHPs raising debt from the market (Scenario 1) would cost government $\$ 11.8$ billion in annual subsidies.

Regularly receiving a stable amount of CRA (as a supplement to the fortnightly receipt of the primary income support payment) is also often crucial for a social security recipient to manage their budget and rent obligations. The financial and emotional impact of a fluctuating income can be high (Morduch and Schneider 2016). We found no research investigating whether sporadic or irregular lumps of income due to delayed or one-off CRA payments-even when received with the primary fortnightly payment-may significantly contribute to a household's income volatility.

A one-off CRA payment may be due to a range of factors: part of the primary payment arrears paid when qualified for an earlier eligibility date; delays in granting CRA while awaiting rent verification (arrears of up to 13 weeks is payable); a component of the reconciliation process of FTB after yearly income is assessed by the ATO; an adjustment due to a change in rent paid, a change in household composition, or a change in earnings notified; arrears due to a suspension being lifted; a transfer to another income support payment. ${ }^{10}$ Depending on the reason and amount, one-off CRA payments may either be expected by a recipient, or may indicate that they had recently experienced a period of income fluctuations that would expose them to heightened financial and emotional risks.

\subsection{Current understandings of the scope and scale of CRA receipt}

CRA is a non-taxable Australian Government supplement to a social security benefit or family payment to people in the private rental market who pay above applicable rent thresholds. To receive CRA, an income unit (a person or couple living in a privately rented dwelling) must receive a primary payment, either Newstart, Disability Support Pension (DSP), Age Pension, Parenting Payment or Austudy/Youth Allowance; or receive a Family Tax Benefit at greater than the base rate. "1 Because CRA is a supplement, it is 'payable' on the same basis as the primary payment. $^{12}$

Supplementary (rent) assistance was introduced in 1958 and was initially restricted to those almost entirely dependent on pensions. It was extended to sickness beneficiaries in 1970 and to unemployment and special beneficiaries in 1986, after they had received the benefit continuously for six months. For beneficiaries, it became less restrictive from 1987 onwards, as well as being extended to low-income families in paid work and receiving the income-tested Family Allowance Supplement. Since 1993, rent assistance has been indexed twice a year to the CPI.

10 See https://guides.dss.gov.au/guide-social-security-law/3/8/1/55.

11 See https://guides.dss.gov.au/guide-social-security-law/3/8/1/10.

12 See https://guides.dss.gov.au/guide-social-security-law/3/8/1/20. 
Tables 2 and 3 show the June 2020 structure of CRA. Payments vary according to income unit status and the presence of dependent children. No assistance is payable for those with rental costs below the fortnightly thresholds shown. Once rental costs are above these levels, social security recipients are paid 75 per cent of their costs up to a maximum level of rent. For those with rental costs above these maximum rent levels, no additional assistance is payable.

Table 2: Structure and rates of rent assistance, people without dependent children, June 2020 (fortnightly figures)

\begin{tabular}{lrrr} 
& Rent threshold & Maximum rent level & Maximum payment \\
\cline { 2 - 4 } Category & $\$$ & $\$$ & $\$$ \\
\hline Single & 124.60 & 310.73 & 139.60 \\
\hline single, sharer & 124.60 & 248.69 & 93.07 \\
\hline couple, combined & 201.80 & 377.27 & 131.60 \\
\hline 1 of a couple separated due to illness & 124.60 & 310.73 & 139.60 \\
\hline 1 of a couple temporarily separated & 124.60 & 300.07 & 131.60 \\
\hline
\end{tabular}

Source: Australian Department of Human Services, https://www.humanservices.gov.au/individuals/services/centrelink/rent-assistance/ how-much-you-can-get.

Note: For people with dependent children, CRA is normally paid with Family Tax Benefit Part A.

Table 3: Structure and rates of rent assistance, people with dependent children, June 2020 (fortnightly figures)

\begin{tabular}{lrrr}
\hline & Rent threshold & Maximum rent level & Maximum payment \\
\cline { 2 - 4 } Category & $\$$ & $\$$ & $\$$ \\
\hline single, with 1 or 2 children & 163.52 & 382.29 & 164.08 \\
\hline single, with 3 or more children & 163.52 & 410.67 & 185.36 \\
\hline a couple, with 1 or 2 children & 241.92 & 460.69 & 164.08 \\
\hline a couple, with 3 or more children & 241.92 & 489.07 & 185.36 \\
\hline
\end{tabular}

Source: Australian Department of Human Services, https://www.humanservices.gov.au/individuals/services/centrelink/rent-assistance/ how-much-you-can-get.

Note: For people with dependent children, CRA is normally paid with Family Tax Benefit Part A.

In December 2019 there were around 1.3 million income units receiving CRA, with more than one million of these being people of working age (DSS 2019). There were around 274,000 income units receiving Newstart Allowance (NSA) and Rent Assistance-around 27 per cent of all working-age CRA recipients. In fact, around 38 per cent of all NSA recipients received CRA, as well as around 53 per cent of families on Parenting Payment Single. These proportions have increased over time; in 2001, the corresponding proportions were 36 per cent and 45.5 per cent respectively. It appears that roughly one-third of all households who are private renters are in receipt of an income support payment or an income-tested family payment.

Table 4 provides details of the people receiving CRA at December 2019 according to the types of social security payments they receive, as well as figures for the average and median rent paid and the average and median level of assistance received.

For example, it can be seen that the median rent paid by NSA recipients was $\$ 400$ per fortnight, while the median assistance received was $\$ 130$ per fortnight. For recipients of Parenting Payment Single, the gap between median rents paid and CRA received is even wider $\mathbf{\$} 600$ in rent compared to $\$ 151$ in Rent Assistance. For rent paid, averages are greater than median values, suggesting a higher proportion of the distribution concentrated towards higher rents. 
This is the opposite for CRA payments, average CRA payment is in most of the cases lower than the median CRA payment, suggesting a higher proportion of the distribution concentrated towards lower CRA payments. Overall, the gap between median rent paid and CRA supplement received is on average \$322.

Table 4: Fortnightly rent and CRA by primary payment type, December 2019

\begin{tabular}{|c|c|c|c|c|c|c|c|c|}
\hline \multirow[b]{3}{*}{ Primary payment type } & \multicolumn{2}{|c|}{ Income units* } & \multicolumn{2}{|c|}{ Rent paid } & \multicolumn{2}{|c|}{ CRA } & \multicolumn{2}{|c|}{$\begin{array}{l}\text { CRA received as a } \\
\text { percentage of rent }\end{array}$} \\
\hline & & & Average & Median & Average & Median & Average & Median \\
\hline & Number & Per cent & $\$$ & $\$$ & $\$$ & $\$$ & $\%$ & $\%$ \\
\hline Disability Support Pension & 259,595 & 20.1 & 428.79 & 390.28 & 125.71 & 138.00 & 29.32 & 35.36 \\
\hline Age Pension & 288,431 & 22.3 & 438.41 & 390.00 & 117.58 & 131.10 & 26.82 & 33.62 \\
\hline Carer Payment & 71,518 & 5.5 & 552.19 & 520.00 & 134.12 & 138.00 & 24.29 & 26.54 \\
\hline Parenting Payment (single) & 120,452 & 9.3 & 595.40 & 600.00 & 138.29 & 151.20 & 23.22 & 25.20 \\
\hline Newstart Allowance & 273,896 & 21.2 & 457.66 & 400.00 & 116.71 & 130.48 & 25.50 & 32.62 \\
\hline Youth Allowance (student) & 36,441 & 2.8 & 385.63 & 350.00 & 100.90 & 92.00 & 26.16 & 26.28 \\
\hline Youth Allowance (other) & 12,284 & 1 & 315.35 & 300.00 & 89.47 & 92.00 & 28.37 & 30.67 \\
\hline Youth Allowance (apprentice) & 606 & 0 & 384.38 & 350.00 & 103.52 & 92.00 & 26.93 & 26.28 \\
\hline Austudy & 13,300 & 1 & 466.69 & 400.00 & 110.99 & 92.00 & 23.78 & 23 \\
\hline Parenting Payment (partnered) & 21,070 & 1.6 & 717.17 & 700.00 & 158.37 & 162.12 & 22.08 & 23.16 \\
\hline Family Tax Benefit (only) & 186,101 & 14.4 & 752.72 & 732.46 & 116.40 & 126.42 & 15.36 & 17.26 \\
\hline Other** & 7,957 & 0.6 & 442.80 & 400.00 & 112.75 & 125.67 & 25.46 & 31.42 \\
\hline All individuals and families & $1,291,651$ & 100 & 508.96 & 460.00 & 121.53 & 138.00 & 23.88 & 30 \\
\hline
\end{tabular}

* An income unit comprises a single person (with or without dependent children) or a couple (with or without dependent children). Single social security recipients living together in the same household are regarded as separate income units. One member of a couple is treated as the reference person for the income unit, based on the type of payment they receive. The general order of priority is Pensions; Allowances; Family Tax Benefit (FTB). Parenting Payment (Partnered) will be reported for income units where one member receives Parenting Payment and their partner is not receiving any other income support payment. They will only be reported as receiving FTB Part $A$ if neither receives a social security payment.

** 'Other' includes payments such as Bereavement Allowance, Sickness Allowance, Special Benefit, Widow Allowance, Emergency Circumstance Payment, etc. Other also includes income units with regular care for children between $14 \%$ and less than $35 \%$ of the time and renting in the private rental market or community housing.

Source: Department of Social Services, DSS Payment Demographic Data, December 2019, https://data.gov.au/data/dataset/dsspayment-demographic-data/resource/1ab39d1b-328a-4311-8b35-ee13c3fodfc7.

In brief, a substantial proportion of the working age population are combining private rent with receipt of social security payments, and potentially part-time or volatile work.

The amount of Rent Assistance a recipient can be paid can change if the rent paid increases or decreases, if recipients move house, if their income increases or decreases, or if their family circumstances change, for example on separation from a partner, or if the number of children in the family changes. As a result, changes in Rent Assistance may reflect the volatility of household incomes or other circumstances that can be associated with housing stress.

DOMINO data potentially allows us to disentangle some of these factors, including whether they move between different postcodes, whether their private earnings change upwards or downwards and whether their household composition changes. Potentially, these changes can then be linked to changes in the amount of Rent Assistance they receive and to measures of housing stress. 


\subsection{Research questions}

One of the main aims of this research is to test the housing-related data capabilities of DOMINO and to investigate the prevalence and potential volatility of within-year CRA receipt in households reliant on NSA, pensions or FTB; and analyse the relationships between selected housing characteristics and the spells these households receive CRA.

We anticipate findings from this project will highlight the significance of including DOMINO-derived income volatility measures in housing research, and alert policy makers of the need to investigate within-year income heterogeneity impacts when developing housing policy, programs and practice. The research questions in this study are presented in Table 5.

The research was carried out in two stages. In Stage 1 we identify for the most recent data in a full year (2016) the proportion of households that receive CRA for short (0-4 months), medium (5-9) and long spells (10+ months) at a national level. We then present the geographical distribution of different profiles of households receiving CRA across regions. In particular, we explore how profiles vary across cohorts, where cohorts are defined by gender and age, as well as by receipt of NSA, pensions and FTB. We then assess the extent to which these cohort's experiences of CRA receipt spells vary across tenure type.

In Stage 2, we discuss how the insights in Stage 1 compare with previous (AHURI) research utilising HILDA, Census and other datasets. Moreover, we discuss how the dataset might be used to gauge the experience of households receiving CRA over the longer term (2000-October 2017), and consider the limitations of this data in informing housing policy.

The results from this project contribute to an understanding of the within-year lived experience of households receiving CRA, and showcase DOMINO as a rich resource for AHURI research. In particular, this pioneering study offers policy makers and researchers a more nuanced appreciation of a potential housing tenure risk facing some of our most vulnerable households and individuals - the timely receipt and adequacy of CRA and of primary income support payments.

Table 5: Research questions

Stage 1 1. What percentage of households receive CRA for short ( $0-4$ months), medium (5-9) and long spells (10+ months)? 2. How does this profile of households receiving CRA for short, medium and long spells vary across regions?

3. How does this profile vary across cohorts, where cohorts are defined by gender and age, as well by receipt of Newstart Allowance and Parenting Payment?

Stage 2 4. How do the insights in Stage 1 resonate with previous (AHURI) research utilising HILDA and Census data bases?

5. How might the dataset be used to gauge the experience of households receiving CRA over the longer term?

Source: Authors. 


\section{Within- and across-year patterns of CRA receipt: initial data insights}

- Within the overall data provided that contained 14.8 million unique recipients, we identified 10,991,479 individuals who received a payment from Centrelink between 2000 and 2017.

- Commonwealth Rent Assistance was paid to over 5 million income units during this period.

- 1,967,028 income units received CRA payments during 2016.

- During 2016, 747,167 income units started receiving CRA and 505,942 ceased receipt.

- On average, CRA recipients most recently received this supplement for 363 days.

- The median period of most recent receipt was far lower-129 days and 51 per cent of CRA recipients most recently received this supplement for less than a year.

- Women have more longer-term recent and common spells on CRA than men. Conversely, men are more likely than women to have most recently and most commonly received CRA in spells of less than a year.

- Women are more likely than men to receive the CRA supplement for periods of 270 days or longer. 
- Newstart recipients were far more likely to have most recently (77\%) received a spell of CRA shorter than a year-reflecting the policy design of this payment. In contrast 72.6 per cent of the most recent CRA spells linked to FTB payments were for more than year-also reflecting the longer-term needs of families with dependent children.

- While the number of people receiving CRA payments per year has increased over time, there are fewer new CRA recipients joining every year. 


\subsection{Data and methods}

\subsubsection{Data}

DSS unit-record data in DOMINO is daily, modular and event-based. That is, the data is primarily comprised of events-each a record of a change that occurred in an individual's circumstances that day which may affect their social security payment eligibility, rate or payability. ${ }^{13}$ There are a wide range of circumstances where an event is recorded, ranging from: changes in household composition and address; adjustments in rates due to the Department's assets and income tests; applying the activity test; compliance with administrative procedures; and transfers to another payment. The period between an event recorded on one day and the next event is therefore not fixed.

Overall, the DOMINO data provided contained complex, internally clustered variables: 20 'member variables' held a range of 'parent variables' which then contained 229 key variables with 3,218 discrete values. There were seven fixed variables: person ID; date of birth and death; gender; country of birth; an Indigenous code; and start date. Only one non-static variable identified-benefit status - contained all recipients in the dataset.

DSS provided 10 separate dataset files containing the selected variables and observations the team requested in the project proposal (see Appendix 2). Each of these data files contained a list of variables and millions of observations (the smallest data file contained over 5 million observations, while the largest contained over 1,560 million observations).

The data files included information on the type of Centrelink benefit received, the period and duration of the benefit payments, as well as some information on benefit recipients, such as: gender, age, family composition, state of residency, ${ }^{14}$ type of accommodation, home ownership status or type and amount of rent paid. Information was also provided on Centrelink payment types and amounts; whether they were one-off or regular payments to recipients, or payments to third parties. ${ }^{15}$

The data was provided for the period between 2000 to October 2017. Approximately 10 per cent of individuals in the dataset had commenced receiving benefits prior to 2000. However, we decided to consider only benefit receipt from January 2000. The benefits most recently closed in the dataset ended in October 2017, with approximately 18 per cent of individuals in the dataset still currently receiving payments (at least to the point when dataset was provided and to our knowledge).

The data was provided through a virtual platform, that required confidentiality and security training, and could be accessed with a series of passwords and codes (see Appendix 1). The data folder was shared in a file between the different team members' virtual computers, allowing simultaneous analysis. Initially, only SAS software was available in this virtual environment to analyse and work with the datasets. Although other statistical software were included on the platform halfway through the project, the large number of observations was better handled with SAS. ${ }^{16}$

13 For a definition of payability see Social Security Guide, 3.1.6.10 General payability provisions, https://guides.dss.gov.au/guide-socialsecurity-law/3/1/6/10.

14 Although variables for postcodes and community codes were provided, they exhibit a large number of missing observations.

15 See Payment Nominee https://guides.dss.gov.au/guide-social-security-law/8/5/1.

16 One negative consequence of using SAS is that the figures generated for this report are quite basic. 


\subsubsection{Methods}

When analysing the data, we merged the different data files across IDs to maintain the information for the same individuals. For this exploratory work we confined analysis to selected static variables plus those listed in Table 6.

Table 6: Variables in focus

\begin{tabular}{l}
\hline Variable \\
\hline Benefit Status \\
\hline Client Benefit Type Code \\
\hline Duration of Episode (Days) \\
\hline End Reason \\
\hline End Reason Code \\
\hline Event End Date \\
\hline Event Start Date \\
\hline Person ID
\end{tabular}

Source: Authors.

Within the Client Benefit Type Code 'parent' variable, five types of Rent Assistance variables were available for analysis (Table 7).

Table 7: CRA variables in focus

\begin{tabular}{ll}
\hline Variable & Label \\
\hline RAF & Rent Assistance Family \\
\hline RAG & Rent Assistance Parenting \\
\hline RAN & Rent Assistance Newstart \\
\hline RAP & Rent Assistance Pension \\
\hline RAS & Rent Assistance Abstudy \\
\hline
\end{tabular}

Source: Authors.

\section{CRA spells and cohorts}

One of the central aims of the research is to identify the periods of time-or spells - that a person received CRA. A time series analysis would have been the most appropriate method. However, this approach was beyond the scope of the exploratory project. Instead we split the sample into CRA recipients receiving payments into the following periods:

- fewer than or equal to 120 days (0-4 months)

- 121 to 270 days (5-9 months)

- 271 to 365 days (10-12 months)

- 366 days to 2 years (1-2 years)

- 2 years and one day to 5 years (2-5 years)

- 5 years and one day 10 years (5-10 years)

- 10 years and one day to 15 years (10-15 years), and

- more than 15 years. 
The sample was also split into three cohorts. This method was driven by the problem that some spell periods were not able to be determined in the sample. Some CRA recipients were still currently receiving payments and therefore we could not define the duration of their payments, and another group seemed less contemporaneous and relevant as their payments commenced before 2000 .

A pragmatic approach was taken to identify and analyse these two groups separately from the rest of the sample as Cohorts 2 and 3. This method provided a practical (but not comprehensive) way to focus on completed spells (Cohort 1) in Section 2.2.4. This pragmatic approach implies that the distribution of spell duration for Cohort 1 may be downward biased due to the censoring performed by only considering those individuals commencing CRA payment in 2000. The cohorts are defined as follows:

- Cohort 1: Persons who were currently not receiving any CRA benefit and have received CRA benefit payment for the period between January 2000 and October 2017 (inclusive).

- Cohort 2: Persons who were currently receiving CRA benefit and have their first CRA benefit payment between the years 2000 and 2017 (inclusive).

- Cohort 3: Persons who currently may or may not be receiving any payments and had their first benefit payment prior to year 2000 .

There was a further issue in this spell and cohort classification. A CRA recipient in a specific cohort may have received several instances of payments for different periods of times. That is, a CRA recipient in Cohort 1 for example, may have received first CRA payment for one year, and then later for only 120 days, and a few years later for 300 consecutive days. A single CRA recipient belonging to one of the cohorts can then be classified under several different payment spell periods. To analyse CRA recipients within this complexity, we have decided to classify them into spells based on:

- their most recent CRA spell, and

- their most common CRA spell.

\section{Limitations}

The CRA variables listed in Table 7 above are used extensively in our exploratory analyses. However, this variable list has significant limitations. Firstly, the Rent Assistance Pension variable does not allow a disaggregated analysis of the Disability Support Pension, Age Pension, Parenting Payment Single and Carer Payment. Secondly, the list does not include CRA supplements attached to Youth Allowance or Austudy. In the DSS December 2019 stock data (see Table 4) 62,631 individuals were recorded as receiving CRA with their Youth Allowance or Austudywhich accounts for 4.9 per cent of the 1,291,651 CRA income units. Our exploratory findings using this specific data list are therefore slightly underestimating the scope and scale of CRA receipt.

Due to the complexities associated with CRA paid to third parties, such as CRA for carers and CRA paid to incapacitated individuals but managed and administered by a third person, this data was also not included in our analysis. ${ }^{17}$

In the initial findings section below we note the variables selected and the different methods applied for specific analyses. All analyses, unless otherwise noted, used the Person ID variable to generate findings based on unique individuals. 


\subsection{Initial findings}

The initial findings are presented in five sub-sections.

- To develop a basic understanding of the scope, scale and characteristics of the data in the sample, a preliminary exploration of CRA records was conducted. These findings provided some insights into the overall distribution of records associated with various income support payments and recipients' characteristics (2.2.1).

- Secondly, we investigated the sample at the unique participant level by cohort and spell to more clearly understand CRA receipt patterns (2.2.2).

- We then present some comparative data on the scale of one-off and regular CRA payments and briefly discuss their potential impact on recipients' financial circumstances (2.2.3)

- Finally, we focused on Cohort 1-those CRA recipients who have received payments between 2000 and 2017 but had stopped receiving the CRA payment by October 2017. We do this because Cohort 2 includes CRA recipients who are still currently receiving payments and therefore we cannot define the duration of that payments, and Cohort 3 seems less contemporaneous and relevant as payments commenced before 2000 (2.2.4).

- A case example of 2016 CRA receipt illustrates the significant difference between flow and stock data analyses (2.2.5).

\subsubsection{CRA records}

From over 77 million payment records, around 10 per cent were still current in October 2017 and 21 per cent of all records correspond to some type of CRA payment (Table 8).

Table 8: CRA records by cohort

\begin{tabular}{ll}
\hline Cohort & Definition \\
\hline 1 & $\begin{array}{l}\text { Persons who are currently not receiving any CRA benefit and have received CRA benefit payment } \\
\text { between the January } 2000 \text { and October } 2017 \text { (inclusive). }\end{array}$ \\
\hline 2 & $\begin{array}{l}\text { Persons who are currently receiving CRA benefit and had their first CRA benefit payment between } \\
\text { the years } 2000 \text { and } 2017 \text { (inclusive). }\end{array}$ \\
\hline 3 & $\begin{array}{l}\text { Persons who currently may or may not be receiving any payments and had their first benefit } \\
\text { payment prior to year 2000. }\end{array}$ \\
\hline Total & \\
\hline
\end{tabular}

Source: Department of Social Services, DOMINO data (Authors' calculations).

Table 9 presents a summary of the CRA payment records of the three cohorts by the benefit type they received (Column 1). The percentages in Columns 2 to 4 are read downwards-showing how the CRA records are distributed within each cohort by benefit type. The percentages in the final column can be read across-showing what proportion of total CRA records are associated with each benefit type.

Overall, Column 5 shows that the majority (57.3\%) of CRA payment records are linked to recipients of Newstart Allowance, with Family Tax Benefit (22.3\%) and Pensions (19.7\%) the other major payments, with Rent Assistance Parenting (0.4\%) and Rent Assistance Abstudy (0.3\%) a small minority. Comparing the distribution of CRA payment records across the cohorts shows some significant variations.

Cohort 1 (people not currently receiving payments) CRA records not unexpectedly comprise the highest proportion of records in the sample (66.5\%). CRA payment records in Cohort 1 are also more strongly connected with individuals receiving Newstart Allowance (63.4\%) than Cohort 2 (38.3\%) or Cohort 3 (55.4\%). It is likely that the main reason for this disproportionally high association of CRA payment records with Newstart in Cohort 1 is due to greater payment volatility. The event-based data identifies payment starts, adjustments and cessation dates. Records of CRA payments linked to Newstart tend to be greater in number because Newstart is most commonly received in short spells - a volatility generating more CRA events (see Table 18). 
Cohort 2 (post-2000 first time recipients currently receiving CRA in October 2017) show a higher than average proportion of CRA records linked to the more stable Family Tax Benefit (32.2\%) and Pension payments (28.6\%). Again, this is unsurprising given that CRA records for this cohort is less likely to exhibit the greater, longer-run CRA record generation of more sporadic payments such as Newstart.

Cohort 3 (pre-2000 CRA recipients) has the highest rate of Pension related CRA records (38\%) which is also expected given that this cohort has historical data where age would have an effect determining that cohort.

Table 9: CRA payment records by payment type (all records)

\begin{tabular}{|c|c|c|c|c|}
\hline Rent Assistance records linked to... & Cohort 1 & Cohort 2 & Cohort 3 & $\begin{array}{l}\text { Proportion of total CRA } \\
\text { records by payment type }\end{array}$ \\
\hline Newstart & $\begin{array}{r}6,751,199 \\
(63.4 \%)\end{array}$ & $\begin{array}{r}1,223,105 \\
(38.3 \%)\end{array}$ & $\begin{array}{r}1,206,026 \\
(55.4 \%)\end{array}$ & $\begin{array}{r}9,180,330 \\
(57.3 \%)\end{array}$ \\
\hline Family Tax Benefit & $\begin{array}{r}2,403,503 \\
(22.6 \%)\end{array}$ & $\begin{array}{r}1,028,095 \\
(32.2 \%)\end{array}$ & $\begin{array}{r}138,548 \\
(6.4 \%)\end{array}$ & $\begin{array}{r}3,570,146 \\
(22.3 \%)\end{array}$ \\
\hline Pension & $\begin{array}{r}1,409,734 \\
(13.2 \%)\end{array}$ & $\begin{array}{r}911,044 \\
(28.6 \%)\end{array}$ & $\begin{array}{r}827,449 \\
(38.0 \%)\end{array}$ & $\begin{array}{r}3,148,227 \\
(19.7 \%)\end{array}$ \\
\hline Parenting Payment Partnered & $\begin{array}{r}44,780 \\
(0.5 \%)\end{array}$ & $\begin{array}{r}21,745 \\
(0.7 \%)\end{array}$ & $\begin{array}{l}2,463 \\
(0.1 \%)\end{array}$ & $\begin{array}{r}71,988 \\
(0.5 \%)\end{array}$ \\
\hline Abstudy & $\begin{array}{r}38,612 \\
(0.4 \%)\end{array}$ & $\begin{array}{l}6,232 \\
(0.2 \%)\end{array}$ & $\begin{array}{l}2,482 \\
(0.1 \%)\end{array}$ & $\begin{array}{r}47,326 \\
(0.3 \%)\end{array}$ \\
\hline Total Sample & $10,650,828$ & $3,190,221$ & $2,176,968$ & $16,018,017$ \\
\hline Proportion of total sample & $66.5 \%$ & $19.9 \%$ & $13.6 \%$ & $100 \%$ \\
\hline
\end{tabular}

Source: Department of Social Services, DOMINO data (Authors' calculations).

Table 10 utilises all CRA payment records to indicate the likely characteristics of CRA recipients by cohort. All cells report proportions based on cohort totals except for the cells in the 'Age' row which reports mean age and age standard deviation in brackets. Based on payment records, the suggested average age of someone who receives a CRA payment is 44. Over half are women (54.7\%), and around 6 per cent are Aboriginal people and/or Torres Strait Islanders. CRA recipients in Cohort 3 are a decade older than those in Cohorts 1 and 2. 25 per cent of CRA recipients were born overseas, mainly in Great Britain, New Zealand, and China.

Table 10: CRA payment records associated with recipients' characteristics

\begin{tabular}{|c|c|c|c|c|}
\hline Recipient Characteristics & Cohort 1 & Cohort 2 & Cohort 3 & Total CRA Sample \\
\hline Women & $57.7 \%$ & $66.5 \%$ & $42.5 \%$ & $54.7 \%$ \\
\hline Age & $\begin{array}{r}42 \text { years } \\
(14.3 \%)\end{array}$ & $\begin{array}{r}46 \text { years } \\
(16.2 \%)\end{array}$ & $\begin{array}{r}55 \text { years } \\
(15.9 \%)\end{array}$ & $\begin{array}{r}44 \text { years } \\
(15.6 \%)\end{array}$ \\
\hline Non-Indigenous & $88.8 \%$ & $89 \%$ & $92 \%$ & $89.3 \%$ \\
\hline Aboriginal and/or Torres Strait Islander & $6.3 \%$ & $5.9 \%$ & $4.6 \%$ & $6 \%$ \\
\hline Country of birth - Australia & $75.9 \%$ & $74.5 \%$ & $75.7 \%$ & $75.6 \%$ \\
\hline Country of birth - Great Britain & $3.8 \%$ & $4.7 \%$ & $6 \%$ & $4.2 \%$ \\
\hline Country of birth - New Zealand & $3.3 \%$ & $3.7 \%$ & $3.1 \%$ & $3.4 \%$ \\
\hline Country of birth - China & $1.2 \%$ & $0.9 \%$ & $1 \%$ & $1.1 \%$ \\
\hline Total Sample & $\begin{array}{r}10,650,828 \\
(66.5 \%)\end{array}$ & $\begin{array}{r}3,190,221 \\
(19.9 \%)\end{array}$ & $\begin{array}{r}2,176,968 \\
(13.6 \%)\end{array}$ & $16,018,017$ \\
\hline
\end{tabular}

Source: Department of Social Services, DOMINO data (Authors' calculations). 
Similarly, Table 11 utilises all CRA payment records to indicate the likely housing characteristics of CRA recipients by cohort. ${ }^{18}$ Most cells report proportions based on cohort totals except for the cells in the 'Weekly rent' row which reports mean weekly rent and weekly rent standard deviation in brackets. Monetary values are aggregated in current prices. The CRA records suggest that nearly 70 per cent of recipients rent privately. Further policy and data investigations beyond the scope of this project are required to understand how CRA records associated with non-home owners suggest that about six per cent of recipients may own a home (which we understood would normally preclude a CRA payment). CRA recipients pay on average \$168.60 per week (nominal terms), and half do not share accommodation with other individuals.

Table 11: CRA and housing

\begin{tabular}{lrrrr}
\hline Housing characteristics & Cohort 1 & Cohort 2 & Cohort 3 & Overall CRA sample \\
\hline Non-home owner & $93.8 \%$ & $95 \%$ & $94.7 \%$ & $94.2 \%$ \\
\hline Private rent & $69 \%$ & $70.9 \%$ & $63.6 \%$ & $68.6 \%$ \\
\hline Lodging only & $8.9 \%$ & $7.2 \%$ & $9.6 \%$ & $8.6 \%$ \\
\hline Board and lodging & $8.4 \%$ & $6.4 \%$ & $10.7 \%$ & $8.3 \%$ \\
\hline Site fees & $3.7 \%$ & $7.2 \%$ & \multicolumn{1}{c}{$6.9 \%$} & $5 \%$ \\
\hline Other housing organisation & $1 \%$ & $3.1 \%$ & $1.7 \%$ & $1.6 \%$ \\
\hline Weekly rent & $\$ 168.60$ & $\$ 193.90$ & $\$ 132.20$ & $\$ 168.60$ \\
& $(\$ 105.50)$ & $(\$ 108.80)$ & $(\$ 73.70)$ & $(\$ 103.60)$ \\
\hline Not shared accommodation & $48.3 \%$ & $59.6 \%$ & $49.6 \%$ & $51.2 \%$ \\
\hline Shared accommodation & $30 \%$ & $18.2 \%$ & $24.9 \%$ & $26.4 \%$ \\
\hline Total sample & $10,650,828$ & $3,190,221$ & $2,176,968$ & $16,018,017$ \\
\hline
\end{tabular}

Source: Department of Social Services, DOMINO data (Authors' calculations).

\subsubsection{CRA recipients}

As preliminary part of our investigation of CRA receipt patterns at the unique individual level we did a scoping analysis of CRA receipt which also included other income support payments. Within an overall sample that contained 14.8 million unique recipients, we identified 10,991,479 individuals who received a payment from Centrelink between 2000 and $2017 .^{19}$

Table 12 summarises how many people were paid the CRA supplement during this period, and how many individuals received (at least) one of the five more common income support payments. There is double counting here for two reasons. Firstly, CRA is not a standalone payment-it is a supplement always attached to a primary payment such as Newstart Allowance, a pension or Family Tax Benefit. Secondly, a person may transition from one payment to another during their life course - such as moving from NSA to a Disability Support Pension (and vice versa).

We provisionally identified 5,039,440 income units who received CRA payments between January 2000 and October 2017. The other baseline findings from the sample — while not directly connected to the CRA—are also highly significant.

18 The housing accommodation categories are: boarder or lodger (BAL), customer selected for data collection mail out (DAT), exempt (EXE), lives with parents (LWP), joint leasing (LWJ), does not live in shared accommodation (NAS), lives in a residential college or hostel in the academic year (RCO), lives with recipient child only (REC), shares accommodation with home owner (SHH), lives in shared accommodation (SHR), and exempt from sharers rate (XSH). So there are some categories that fall outside or do not specify whether accommodation is shared or not shared.

19 Using Table 6 variables. 
For example, the scale of Newstart Allowance receipt (4.3 million individuals) over the period contributes to challenging the 'them and us' idea that this social security payment is confined to a group of unfortunate individuals and families living at the margins of society (Whiteford 2017). Social security, like health and education, is a core part of mainstream Australian life. These initial findings reflect survey research by the Melbourne Institute showing that more than 70 per cent of Australian families with a working age member received an income support payment (excluding family payments and the Age Pension) between 2001 and 2015 (Wilkins 2017: 40).

Table 12: Number of people receiving selected payments 2000-2017

\begin{tabular}{lr}
\hline Payment & Individuals \\
\hline AGE & $3,884,268$ \\
\hline CRA $^{20}$ & $5,039,440^{21}$ \\
\hline DSP & $1,599,280$ \\
\hline NSA & $4,267,844$ \\
\hline PPP & $1,391,657$ \\
\hline PPS & $1,338,932$ \\
\hline
\end{tabular}

Source: Department of Social Services, DOMINO data (Authors' calculations).

Table 13 identifies the total number of unique CRA recipients in each cohort. Of the 11 million individuals receiving a Centrelink payment in the sample, approximately half were paid CRA. Since 2000, there have been 4,493,220 Australians receiving CRA (Cohorts 1 and 2), of which only 20.5 per cent still currently receive the benefit as of the last data update, October 2017.

Of these 5 million CRA recipients, 71 per cent (3.5 million) received a payment between 2000 and 2017 but are not currently receiving any CRA payments (Cohort 1). In addition, 18 per cent (over 920,000 people) were receiving a CRA payment in October 2017 and had received their first payment after January 2000 (Cohort 2). A further 11 per cent (over half a million) people started receiving CRA payments before 2000 (Cohort 3). Most of this latter cohort (93.7\%) currently received CRA payments-that is, they were receiving CRA in October 2017.

Table 13: CRA recipients by cohort

\begin{tabular}{ll}
\hline Cohort & Definition \\
\hline 1 & $\begin{array}{l}\text { Persons who were currently not receiving any CRA benefit and have received CRA benefit } \\
\text { payment between January } 2000 \text { and October } 2017 \text { (inclusive). }\end{array}$ \\
\hline 2 & $\begin{array}{l}\text { Persons who were currently receiving CRA benefit and have their first CRA benefit payment } \\
\text { between the years } 2000 \text { and } 2017 \text { (inclusive). }\end{array}$ \\
\hline 3 & $\begin{array}{l}\text { Persons who currently may or may not be receiving any payments and have their first benefit } \\
\text { payment prior to year 2000. }\end{array}$ \\
\hline Total & \\
\hline
\end{tabular}

Source: Department of Social Services, DOMINO data (Authors' calculations).

20 CRA is a supplementary payment so it is always linked to an income support payment.

21 Income units. 
Analysis of CRA in Table 14 below shows the frequency and proportion of the CRA spells when measured based on the duration of their most recent CRA payment spell. This table describes the number and proportion of unique CRA recipients in each CRA payment spell. Spells are defined as the CRA payment duration (in number of days) of the most recent (or last) CRA payment instance. In general, the most recent CRA benefit spell experienced by a recipient is quite short. Fifty-one per cent of recipients most recently received this payment for less than a year. Fewer than one in five (19.7\%) had most recently been receiving CRA for over two years.

Table 14: Last CRA spell

\begin{tabular}{llrr}
\hline Spell & & Frequency & Percentage \\
\hline Short & 0 to 120 days (0-4 months) & $1,567,708$ & $31.1 \%$ \\
\hline Medium & 121 to 270 days (5-9 months) & 693,953 & $13.8 \%$ \\
\hline Long & 271 to 365 days (10-12 months) & 305,410 & $6.1 \%$ \\
\cline { 2 - 4 } & 1 to 2 years & 387,659 & $7.7 \%$ \\
\cline { 2 - 4 } & 2 to 5 years & 425,125 & $8.4 \%$ \\
\cline { 2 - 4 } & 5 to 10 years & 199,270 & $4 \%$ \\
\cline { 2 - 4 } & 10 to 15 years & 59,246 & $1.2 \%$ \\
\cline { 2 - 4 } & More than 15 years & 350,852 & $6.1 \%$ \\
\hline Current & & $\mathbf{1 , 0 5 0 , 2 1 7}$ & $20.8 \%$ \\
\hline Total & & $5,039,440$ & $100 \%$ \\
\hline
\end{tabular}

Source: Department of Social Services, DOMINO data (Authors' calculations).

We also defined spells based on the most common spell duration a CRA recipient experienced (Table 15).

Table 15: Most common CRA spell

\begin{tabular}{|c|c|c|c|}
\hline Spell & & Frequency & Percentage \\
\hline Short & 0 to 120 days (0-4 months) & 812,652 & $16.1 \%$ \\
\hline Medium & 121 to 270 days (5-9 months) & 701,895 & $13.9 \%$ \\
\hline \multirow[t]{6}{*}{ Long } & 271 to 365 days (10-12 months) & 376,453 & $7.5 \%$ \\
\hline & 1 to 2 years & 470,721 & $9.3 \%$ \\
\hline & 2 to 5 years & 532,584 & $10.6 \%$ \\
\hline & 5 to 10 years & 243,140 & $4.8 \%$ \\
\hline & 10 to 15 years & 65,556 & $1.3 \%$ \\
\hline & More than 15 years & 778,140 & $15.4 \%$ \\
\hline Current & & 1,058, 299 & $21 \%$ \\
\hline Total & & $5,039,440$ & $100 \%$ \\
\hline
\end{tabular}

Source: Department of Social Services, DOMINO data (Authors' calculations).

That is, if a CRA recipient received several CRA benefit payments over time, for different time durations, we classify that specific CRA recipient in the most frequent or common spell duration they exhibit. 
Table 15 describes the number and proportion of unique CRA recipients in each CRA payment spell. Spells are defined as the CRA payment duration (in number of days) of the most common CRA payment instance. Over a third (37.5\%) of recipients most commonly received CRA for less than a year. Clearly this classification considers the payment history of the individual and gives more weight to long term CRA recipients, with 32.1 per cent most commonly receiving CRA for more than two years.

Table 16 provides descriptive statistics for the CRA payment duration (in number of days), by cohort, based on the most recent (or last) CRA payment instance. The table reports the mean, standard deviation (S.D), first quartile (Q1, 25\% of the distribution), median (50\% of the distribution), and third quartile (Q3, 75\% of the distribution) for the number of days an individual received CRA payment in their most recent (last) CRA payment.

Individuals in Cohort 3 have received payments for the longest duration as this cohort contains historical data including CRA recipients before 2000. On average CRA recipients received CRA payments for around a year. There is a very high coefficient of variation (averaging 1.8) across all cohorts. While 25 per cent of CRA recipients received payments for less than 38 days, another 25 per cent of CRA recipients received payments for more than 950 days.

Table 16: Most recent CRA payment duration

\begin{tabular}{|c|c|c|c|c|c|}
\hline Payment duration & Mean & S.D. & Q1 & Median & Q3 \\
\hline Cohort 1 & 318 days & (569.5 days) & 36 days & 114 days & 331 days \\
\hline Cohort 2 & 383 days & (631 days) & 40 days & 143 days & 425 days \\
\hline Cohort 3 & 576 days & (939 days) & 56 days & 215 days & 642 days \\
\hline Total sample & 363 days & (647.5 days) & 38 days & 129 days & 950 days \\
\hline
\end{tabular}

Source: Department of Social Services, DOMINO data (Authors' calculations).

We then focused on the individual's income support payment with which the CRA supplement was paid. ${ }^{22}$ Tables 17 and 18 below describe the most recent and most common spells of CRA payments each individual received (grouped by cohort and payment type).

The final column in Table 17 shows that the most recent spell of CRA was paid as a supplement to 2.1 million Newstart Allowance recipients, 1.5 million families on FTB, and 1.4 million pensioners. Among post-2000 first time recipients currently receiving CRA (Cohort 2) only 12.5 per cent are on Newstart. The bulk of current CRA recipients received this payment as a supplement to either their FTB (41.6\%) or pension (45.5\%).

In contrast, among post-2000 first time recipients not currently receiving CRA (Cohort 1) over half (51.5\%) were on Newstart Allowance, less than a third (30.3\%) received CRA as a supplement to their FTB, and 17.5 per cent received a pension-linked CRA payment. 
2. Within- and across-year patterns of CRA receipt:

initial data insights

Table 17: Most recent CRA spell by income support payment type

\begin{tabular}{lrrrr}
\hline Benefit Type & Cohort 1 & Cohort 2 & Cohort 3 & Total CRA sample \\
\hline Rent Assistance Newstart & $1,839,678$ & 115,155 & 154,428 & $2,109,261$ \\
& $(51.5 \%)$ & $(12.5 \%)$ & $(28.3 \%)$ & $(41.9 \%)$ \\
\hline Rent Assistance Families & $1,083,667$ & 382,448 & 42,348 & $1,508,463$ \\
& $(30.3 \%)$ & $(41.6 \%)$ & $(7.8 \%)$ & $(30 \%)$ \\
\hline Rent Assistance Pensioners & 624,831 & 418,933 & 348,764 & $1,392,528$ \\
& $(17.5 \%)$ & $(45.5 \%)$ & $(63.9 \%)$ & $(27.6 \%)$ \\
\hline Rent Assistance Parenting & 14,310 & 3,141 & 454 & 17,905 \\
& $(<1 \%)$ & $(<1 \%)$ & $(<1 \%)$ & $(0 \%)$ \\
\hline Rent Assistance Abstudy & 10,355 & 702 & 226 & 11,283 \\
& $(<1 \%)$ & $(<1 \%)$ & $(<1 \%)$ & $(0 \%)$ \\
\hline Total sample & $3,572,841$ & 920,379 & 546,220 & $5,039,440$ \\
& $(70.9 \%)$ & $(18.3 \%)$ & $(10.8 \%)$ & $(100 \%)$ \\
\hline
\end{tabular}

Source: Department of Social Services, DOMINO data (Authors' calculations).

Table 18 describes the most common period or spell of CRA payments each individual received (grouped by cohort and payment type). The final column suggests a significant shift towards FTB-linked rent assistance. About 90,000 more people experienced their longest CRA spell whilst an FTB recipient than their most recent spell indicates.

Table 18: Most common CRA spell by payment type

\begin{tabular}{lrrrr}
\hline Benefit type & Cohort 1 & Cohort 2 & Cohort 3 & Total CRA sample \\
\hline Rent Assistance Newstart & $1,816,445$ & 114,865 & 176,257 & $2,107,567$ \\
& $(50.8 \%)$ & $(12.5 \%)$ & $(32.3 \%)$ & $(41.8 \%)$ \\
\hline Rent Assistance Families & $1,168,937$ & 389,925 & 37,231 & $1,596,093$ \\
& $(32.7 \%)$ & $(42.4 \%)$ & $(6.8 \%)$ & $(31.7 \%)$ \\
\hline Rent Assistance Pensioners & 567,139 & 414,699 & 332,354 & $1,314,192$ \\
& $(15.3 \%)$ & $(45.1 \%)$ & $(60.8 \%)$ & $(26.1 \%)$ \\
\hline Rent Assistance Parenting & 7,218 & 190 & 74 & 7,482 \\
& $(<1 \%)$ & $(<1 \%)$ & $(<1 \%)$ & $(0 \%)$ \\
\hline Rent Assistance Abstudy & 13,102 & 700 & 304 & 14,106 \\
& $(<1 \%)$ & $(<1 \%)$ & $(<1 \%)$ & $(0 \%)$ \\
\hline Total sample & $3,572,841$ & 920,379 & 546,220 & $5,039,440$ \\
& $(70.9 \%)$ & $(18.3 \%)$ & $(10.8 \%)$ & $(100 \%)$ \\
\hline
\end{tabular}

Source: Department of Social Services, DOMINO data (Authors' calculations).

CRA recipients have received on average 3.2 spells of CRA payments during the period under investigation, and 50 per cent have received 2 spells of CRA payments. Figure 1 below shows the accumulated total amount of CRA payments accrued by years of receipt. Over two-thirds (70\%) of those who received CRA between January 2000 and October 2017 received less than three years total accrued CRA payments. 
2. Within- and across-year

patterns of CRA receipt:

initial data insights

Figure 1: Histogram of total accrued CRA payments by years

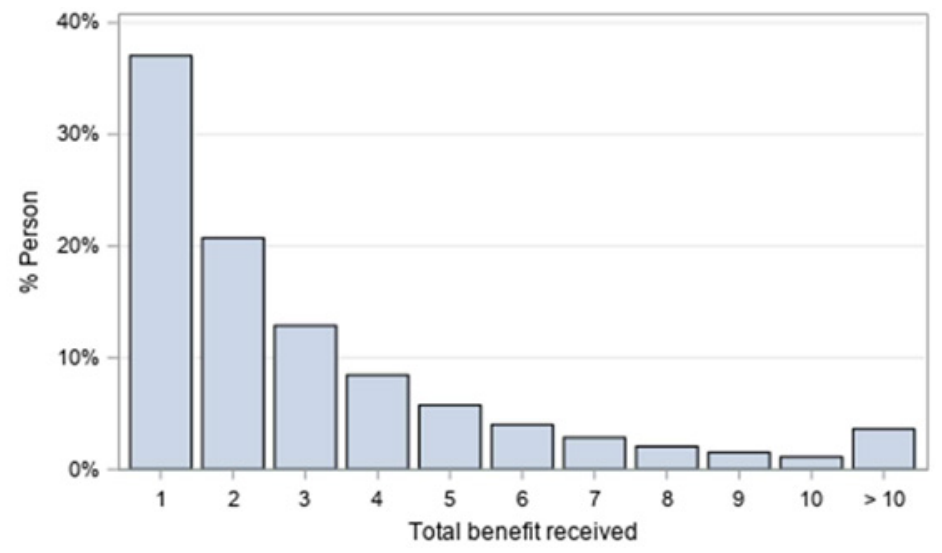

Source: Department of Social Services, DOMINO data (Authors' calculations).

\subsubsection{The scale and scope of one-off CRA payments}

As raised in Section 1.3, we could find no research that has investigated the scale and scope of one-off Rent Assistance payments. We have argued that the financial and emotional impact of a fluctuating income can be high (Morduch and Schneider 2016).

A one-off CRA payment may be due to a range of factors: part of the primary payment arrears paid when qualified for an earlier eligibility date; delays in granting CRA while awaiting rent verification (arrears of up to 13 weeks is payable); a component of the reconciliation process of FTB after yearly income is assessed by the ATO; an adjustment due to a change in rent paid, a change in household composition, or a change in earnings notified; arrears due to a suspension being lifted; or a transfer to another income support payment. ${ }^{23}$ Depending on the reason and amount, one-off CRA payments may either be expected by a recipient, or may indicate that they had recently experienced a period of income fluctuations that would expose them to heightened financial and emotional risks.

This exploratory study provides some preliminary insights into whether sporadic or irregular lumps of income due to delayed or one-off CRA payments may significantly contribute to a household's income volatility. Further qualitative and statistical investigation is required before any assessment can be made whether these one-off payments may have benign or significant impacts.

Table 19 provides descriptive statistics on CRA regular and one-off payments across all three cohorts. The table reports the mean, standard deviation, and median (50\% of the distribution) for daily CRA regular payments and one-off total CRA payments. Monetary values are aggregated in current prices. ${ }^{24}$

Individuals in Cohort 1 received $\$ 11.30$ daily rate on average as CRA regular payments, and $\$ 93.30$ on average as a one-off payment. These payments represent on average 45 per cent of the daily rent, based on calculations in Table 12. However, there is larger variability as reflected on standard deviations.

23 See https://guides.dss.gov.au/guide-social-security-law/3/8/1/55.

24 Prices are not adjusted for inflation. 


\begin{tabular}{|c|c|c|c|}
\hline & Mean & $\begin{array}{l}\text { Standard } \\
\text { deviation }\end{array}$ & Median \\
\hline & $\$$ & $\$$ & $\$$ \\
\hline \multicolumn{4}{|c|}{ Regular payment amount (daily rate) } \\
\hline Cohort 1 & 11.30 & $(12.00)$ & 6.70 \\
\hline Cohort 2 & 12.50 & $(14.20)$ & 7.00 \\
\hline Cohort 3 & 12.50 & $(14.60)$ & 5.50 \\
\hline Total sample & 12.50 & (13.60) & 6.90 \\
\hline \multicolumn{4}{|c|}{ One-off payment amount } \\
\hline Cohort 1 & 93.30 & $(396.60)$ & 5.70 \\
\hline Cohort 2 & 100.00 & $(462.10)$ & 6.50 \\
\hline Cohort 3 & 78.50 & $(283.80)$ & 17.20 \\
\hline Total sample & 94.10 & $(410.50)$ & 6.70 \\
\hline
\end{tabular}

Source: Department of Social Services, DOMINO data (Authors' calculations).

Most CRA recipients appear to have received at least once a one-off irregular CRA payment. Among CRA recipients in Cohort 1, 90.1 per cent received a one-off payment at least once. For Cohort 2, 96.1 per cent received a one-off payment at least once, as had 84.1 per cent of CRA recipients in Cohort 3.

While the median amount of one-off payments is quite low across the cohorts ( $\$ 5.70$ to $\$ 17.20$ ), the average is much higher ( $\$ 78.50$ to $\$ 100.00$ ). Most noticeable is the far wider spread of amounts typically paid as one-off payments that would be highly disruptive to a household's income stability, with a standard deviation from the average of $\$ 396.60$ for Cohort $1, \$ 462.10$ for Cohort 2 and $\$ 283.80$ for Cohort 3.

In the next section focusing on Cohort 1 a more detailed analysis of one-off payments (see Figures 18 and 19) shows high average amounts of one-off CRA payments ( $\$ 500$ to over $\$ 2,000$ ) received by recipients with recent and common spells of over 270 days and under 15 years. Whether this is a major concern-given the harmful impacts of income volatility described in the introductory section of this report-can only be answered by further research.

\subsubsection{Cohort 1 analysis}

We concentrate the rest of the analysis, and address the research questions, on Cohort 1- those CRA recipients who have received payments between January 2000 and October 2017 but have stopped receiving CRA payments since (at least up to the data provided for the research). We do this because Cohort 2 includes CRA recipients who are still currently receiving payments and therefore we cannot define the duration of those payments, and Cohort 3 seems less contemporaneous and relevant, as payments commenced before 2000.

Cohort 1 exhibits over 3.5 million individuals receiving CRA payments between January 2000 and October 2017, and not currently receiving CRA. Figure 2 below shows the number of people (in Cohort 1) receiving CRA payments in a given year. If an individual received two different CRA payment instances in one year, then it is counted as one individual. However, if an individual received a CRA payment instance in one year and then another CRA payment instance in another year, that individual is counted twice. The last data entry was provided for October 2017, so the data for 2017 is incomplete.

Clearly the number of people receiving CRA payments per year has increased over time, but this is mainly due to individuals still receiving the payments over time, with fewer newer CRA recipients joining every year. 
Figure 2: Number of people (Cohort 1) receiving CRA per year (accumulated)

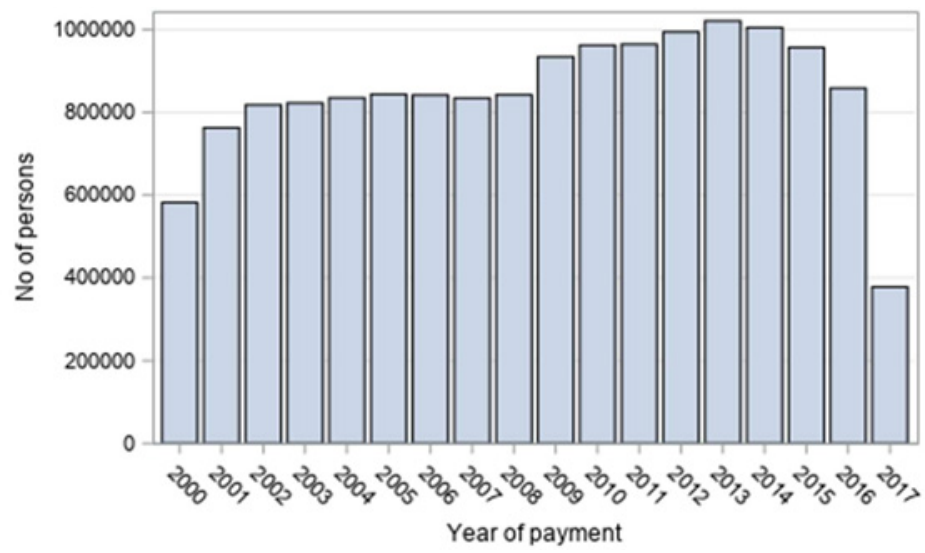

Source: Department of Social Services, DOMINO data (Authors' calculations).

Table 20 below shows the proportion of CRA recipients in Cohort 1 by Centrelink payment type (Newstart, Families, Pensioners, Parenting and Abstudy) ${ }^{25}$ and by spell duration of their most recent (last) CRA payment instance. Proportions are relative to benefit type (column) totals (and can be read vertically by adding the rows of each benefit type to reach $100 \%$ ). However, the last row shows proportions of benefit types relative to total individuals in Cohort 1 (and can be read horizontally by adding the cells of each benefit type to reach $100 \%$ ).

Between 2000 and 2017, 27 per cent of recipients received their last spell of CRA for less than 120 days, and the most recent CRA spell for almost half (48.6\%) was under a year. A further 38.5 per cent received payments between 1 and under 10 years. Newstart recipients were far more likely to have most recently (77\%) received a spell of CRA shorter than a year-reflecting the policy design of this payment. In contrast 72.6 per cent of the most recent CRA spells linked to FTB payments were for more than year-also reflecting the longer term needs of families with dependent children.

Table 20: Last spell and CRA type for Cohort 1

\begin{tabular}{|c|c|c|c|c|c|c|}
\hline & $\begin{array}{r}\text { Newstart } \\
\text { CRA }\end{array}$ & $\begin{array}{r}\text { Families } \\
\text { CRA }\end{array}$ & $\begin{array}{r}\text { Pensioners } \\
\text { CRA }\end{array}$ & $\begin{array}{r}\text { Parenting } \\
\text { CRA }\end{array}$ & $\begin{array}{r}\text { Abstudy } \\
\text { CRA }\end{array}$ & Total \\
\hline Last spell & $\%$ & $\%$ & $\%$ & $\%$ & $\%$ & $\%$ \\
\hline 0 to 120 days (0-4 months) & 48.5 & 10.2 & 18.2 & 83.2 & 34.5 & 27.3 \\
\hline 121 to 270 days (5-9 months) & 20 & 10.5 & 11.2 & 9.6 & 23.7 & 14.4 \\
\hline 271 to 365 days (10-12 months) & 8.1 & 6.8 & 5.1 & 3 & 12.2 & 6.9 \\
\hline 1 to 2 years & 8.2 & 15.1 & 10.6 & 1.6 & 9.9 & 11.3 \\
\hline 2 to 5 years & 5.8 & 24.9 & 20.2 & 0.7 & 7.6 & 16.2 \\
\hline 5 to 10 years & 0.7 & 17.1 & 19.1 & 0 & 0.2 & 11 \\
\hline 10 to 15 years & 0.1 & 4.9 & 7.7 & 0 & 0 & 3.6 \\
\hline More than 15 years & 8.7 & 10.6 & 7.8 & 1.8 & 11.9 & 9.2 \\
\hline Total & 39.4 & 37.8 & 22.3 & 0.25 & 0.24 & 100 \\
\hline
\end{tabular}

Source: Department of Social Services, DOMINO data (Authors' Calculations)

25 See Table 7. 
Further insights are found by comparing the most recent CRA spell to the most common CRA spell experienced by individuals across 2000 to 2017. Figure 3 shows the proportion of people (in Cohort 1) receiving CRA payments, measured in days and years, based on their most recent (last) CRA payment spell. Figure 4 shows the proportion of people (in Cohort 1) receiving CRA payments based on their most common (most frequent) CRA payment spell.

A comparison between both figures highlights that a long term reliance on CRA payments is a far more common experience than a CRA recipient's most recent spell suggests. About 18 per cent of Cohort 1 recipients have experienced relying more frequently on CRA for more than 15 years, compared to 9.2 per cent who had most recently experienced a $15+$ year spell.

Figure 3: Spell duration by last spell (Cohort 1)

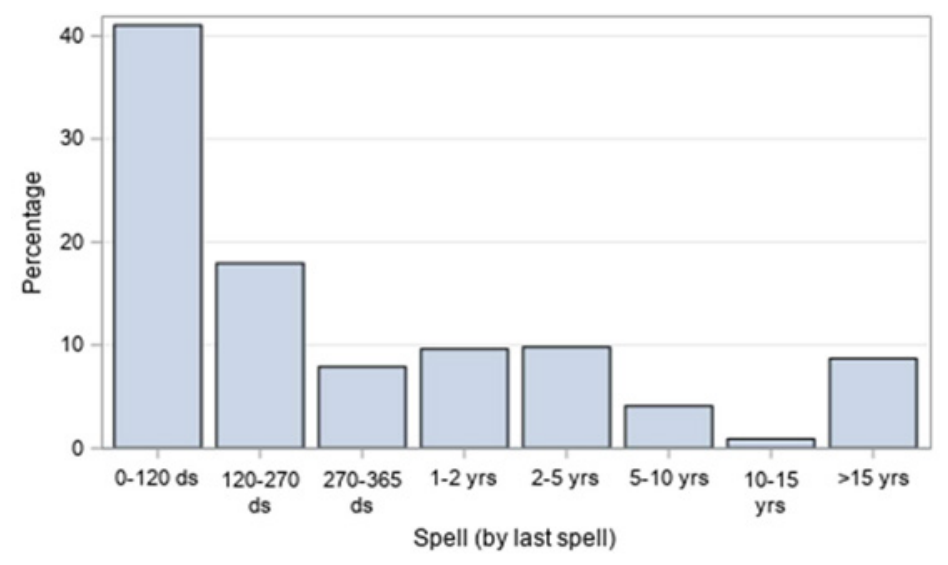

Source: Department of Social Services, DOMINO data (Authors' calculations).

Figure 4: Spell duration by most common spell (cohort 1)

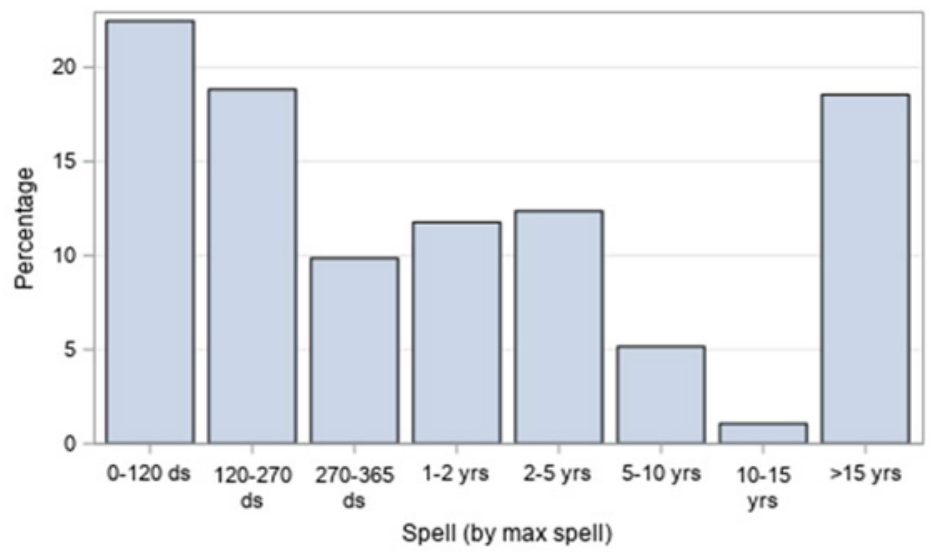

Source: Department of Social Services, DOMINO data (Authors' calculations).

Figure 5 shows the proportion of CRA recipients in Cohort 1 by benefit type and by spell durations. The spell durations, measured in days and years, are based on the most recent (last) CRA payment instance. The benefit type categories are as follows: rent assistance families (RAF), rent assistance parenting (RAG), rent assistance Newstart (RAN), rent assistance pensioners (RAP), and rent assistance Abstudy (RAS).

We find that most individuals receiving Newstart rent assistance tend to receive CRA for a relatively short duration-76 per cent received payments for less than a year (see also Table 21). In contrast, income units on Family Tax Benefit are more likely to be recently receiving CRA payments for longer periods - 57 per cent received payments between 1 and under 10 years. 
The gendered characteristics of long term CRA reliance is stark, given that women are far more likely than men to have household-level income support payment such as FTB and CRA. ${ }^{26}$ Pensioners seem to receive CRA payment for more diverse durations - while over a third received payments for under a year, 50 per cent received payments between 1 and under 10 years, and a further quarter received CRA payments for more than 10 years. Parenting and Abstudy benefit recipients, although only representing a small proportion of CRA recipients, received CRA payments for short periods too.

Figure 5: CRA payment type by last spell (Cohort 1)

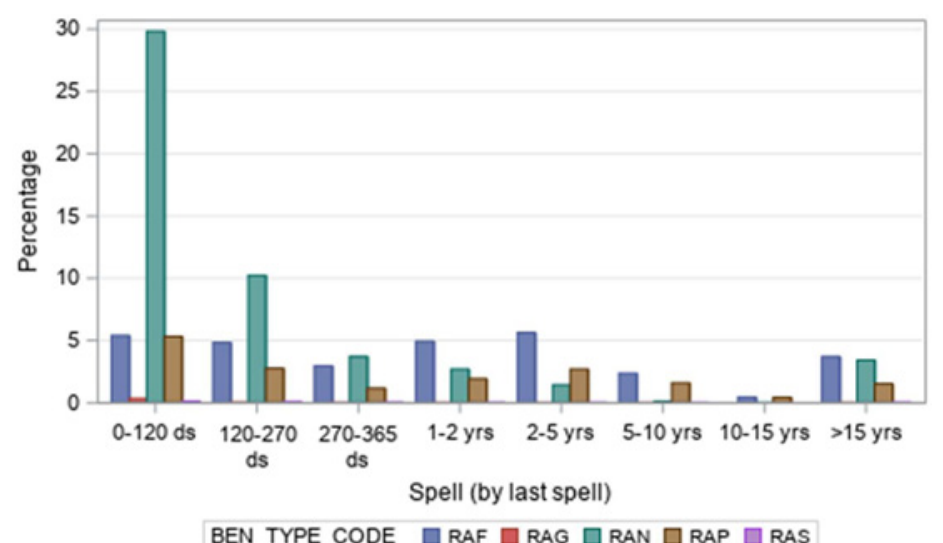

Source: Department of Social Services, DOMINO data (Authors' calculations).

Figure 6 shows the proportion of CRA recipients in Cohort 1 by benefit type and by most common spell duration. Compared to last CRA spell patterns, there is a markedly higher proportion of long term (15+ years) Newstart-linked CRA payment spells. The most common FTB-linked CRA payment spells also lengthen significantly-again reinforcing the dominant role of women in child rearing.

Figure 6: CRA payment type by most common spell (Cohort 1)

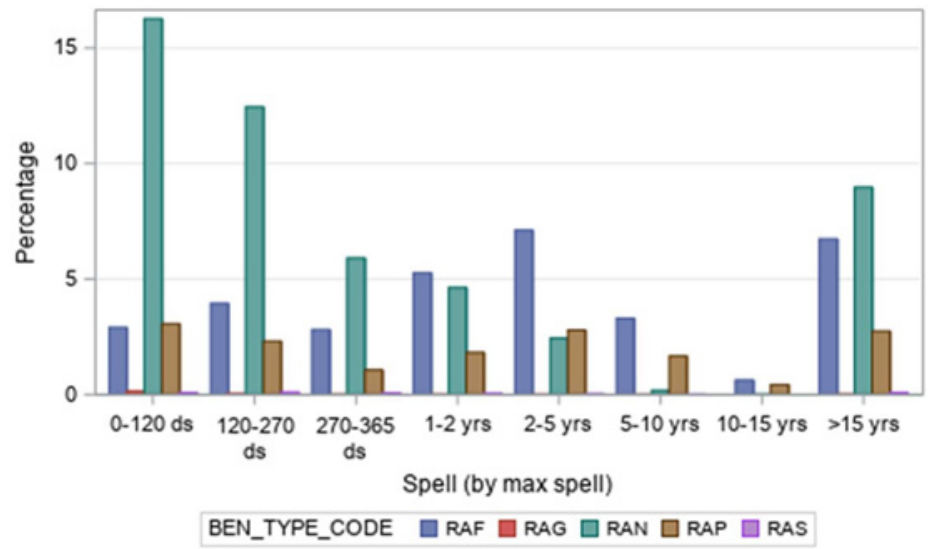

Source: Department of Social Services, DOMINO data (Authors' calculations).

Figure 7 shows box-plots for CRA recipients' age distribution across number of CRA instances received for Cohort 1. Box-plot graphs show the distribution of a continuous variable-in this case age. In particular it shows minimum, maximum values (to comply with data management requirements, we provide minimum and maximum after cutting 5 per cent of the top and bottom of the distribution), means (with a diamond shape), medians (lines inside the shaded boxes) as well as first quartiles (bottom 25\% of the distribution) and third quartiles (top $75 \%$ of the distribution) (limits of the shaded boxes). 
The left graph reports the age distribution of CRA recipients based on the age they were at the start of their first CRA payment. The graph on the right reports the age distribution of CRA recipients based on the age they were at the end of their CRA payments (individuals in Cohort 1 do not currently receive any CRA payment).

CRA recipients in Cohort 1 are on average 37 years old, and half of them are in their thirties when they start receiving a CRA spell. Long term spell recipients are older logically. Interestingly, we observe that individuals receiving fewer instances of CRA payments tend to be older when commencing a CRA payment instance; see the first panel in Figure 7. Those who received more than 5 instances of CRA payments started receiving CRA benefits in their early 30s on average, however those who only had a single CRA payment spell started receiving the payments in their late 30s. Similarly, individuals receiving fewer instances of CRA payments seem to be younger at the time when payments stop; see the second panel in Figure 9. While individuals stop receiving CRA payment instances on average in their early 40s, those receiving between 3-5 CRA payment spells stop receiving them in their late 30s.

Figure 7: Age distribution of CRA at start date and end date, by number of payments spells (Cohort 1)
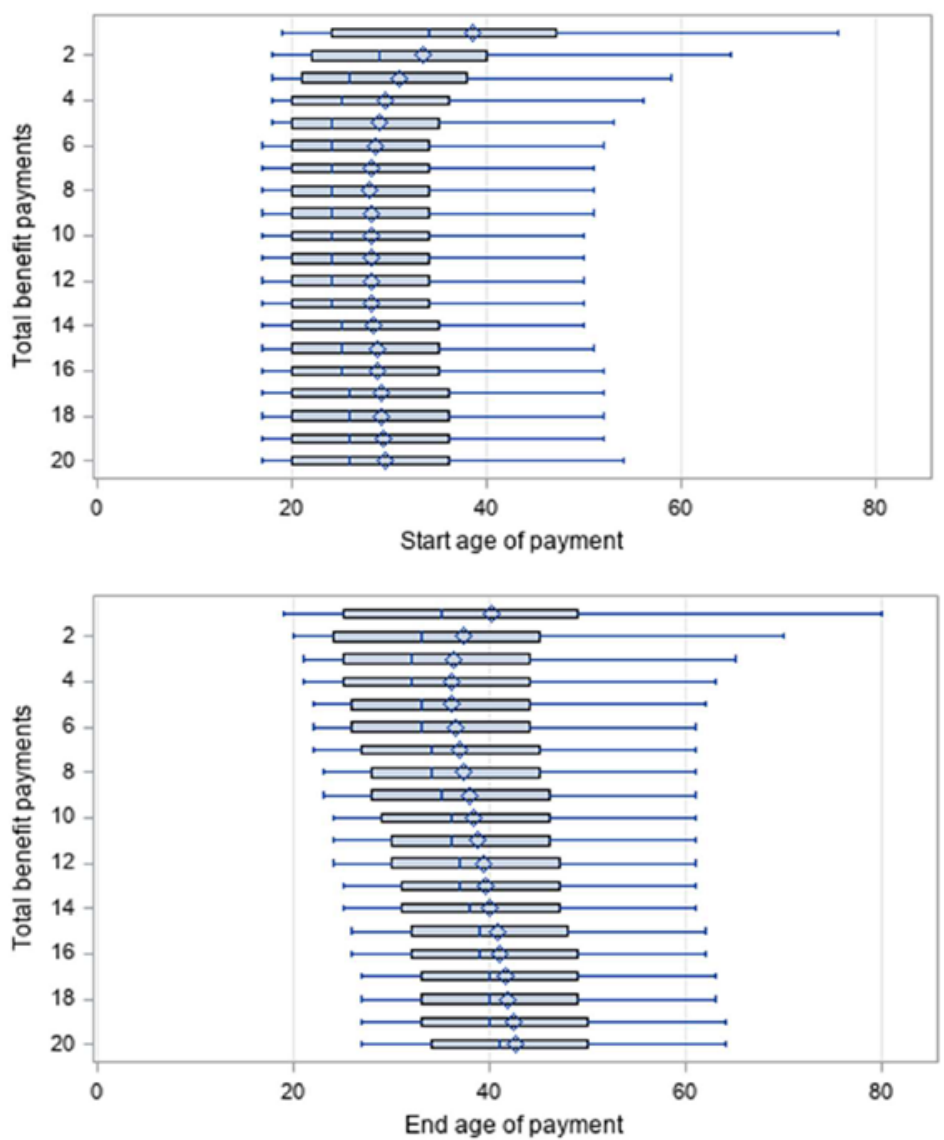

Source: Department of Social Services, DOMINO data (Authors' Calculations).

The age distribution of CRA recipients by number of instances finds that CRA recipients with few payment instances start receiving the payment on average in their late 30s (with a median in their mid-30s), while those with more than five CRA payment instances started receiving the CRA on average in their early 30s (with a median in their mid-20s). Also, on average, those receiving CRA payments for more than fifteen years started receiving the payments in their 30s.

Figure 8 shows the proportion of CRA recipients in Cohort 1 by gender and by spell durations. The spell durations, measured in days and years, are based on the most recent (last) CRA payment instance. Figure 9 shows the proportion of CRA recipients in Cohort 1 by gender and their most common CRA spell duration. 
Comparing these two figures reveals that women have more longer term recent and common spells on CRA than men. Conversely, men are more likely than women to have most recently and most commonly received CRA in spells of less than a year. These important findings are likely due to women's dominant unpaid caring roles and their lower pay in the labour market. Women's longer term receipt of CRA reflects these social and economic facets of gender relations through a higher long term reliance on FTB and income support payments than men, and lower earnings and employment rates. ${ }^{27} \mathrm{~A}$ more detailed analysis by age and gender and payment type (especially Parenting Payment Single and Partnered) would likely explain why women have a greater reliance on the CRA supplement.

Figure 8: Proportion of CRA recipients by last spell and gender (Cohort 1)

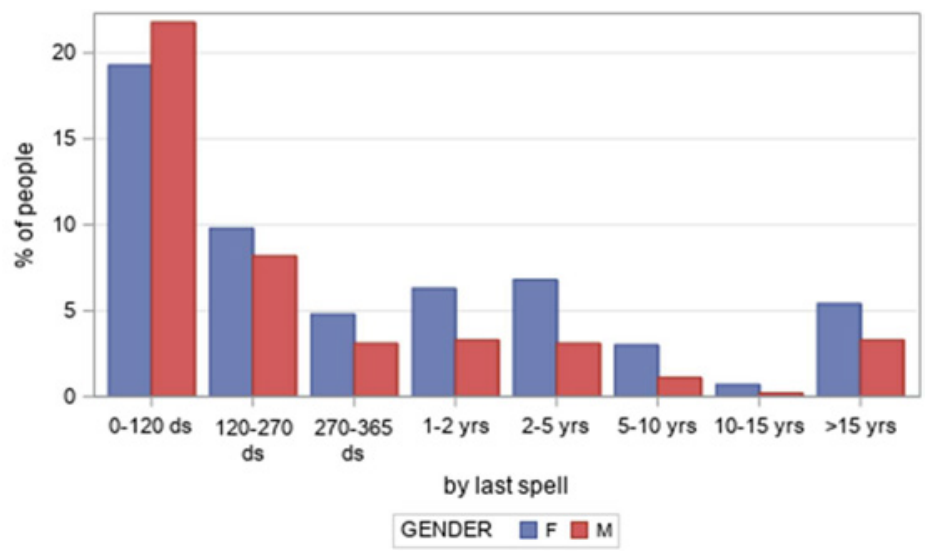

Source: Department of Social Services, DOMINO data (Authors' calculations).

Figure 9: Proportion of CRA recipients by most common spell and gender (Cohort 1)

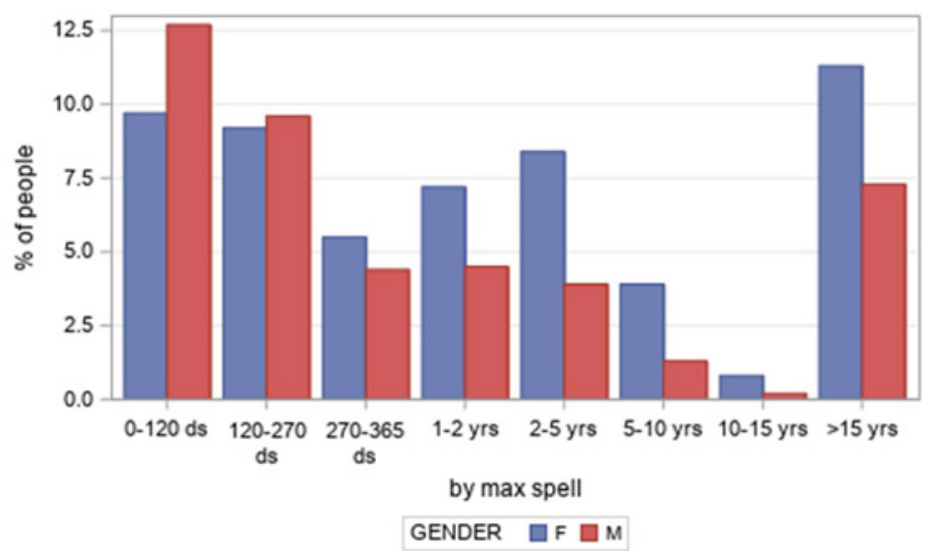

Source: Department of Social Services, DOMINO data (Authors' calculations).

When observing the distribution of CRA recipients by most recent (Figure 10) and most common (Figure 11) spell lengths across states, we observe some disparity between regions. Figure 10 shows that NSW has the largest proportion of CRA recipients for all spell durations. QLD has the second highest proportion for short term spells and longer term spells, however VIC has the second highest proportion for CRA spells between 270 days and 2 years. It is clear that the three main top CRA recipient states are NSW (30.5\%), QLD (24.2\%) and VIC (22.1\%). They are followed by WA, SA, TAS, NT and ACT.

27 See pages 50-52, 57 and 63 https://melbourneinstitute.unimelb.edu.au/hilda/publications/hilda-statistical-reports. 
Though more dispersed, there is a similarly weighted spell pattern when most common CRA spells across states is examined (Figure 11). However, compared to most recent spells, NSW has a relatively higher proportion of long term (15+ years) recipients than other states.

Figure 10: CRA recipients by most recent spell across states (Cohort 1)

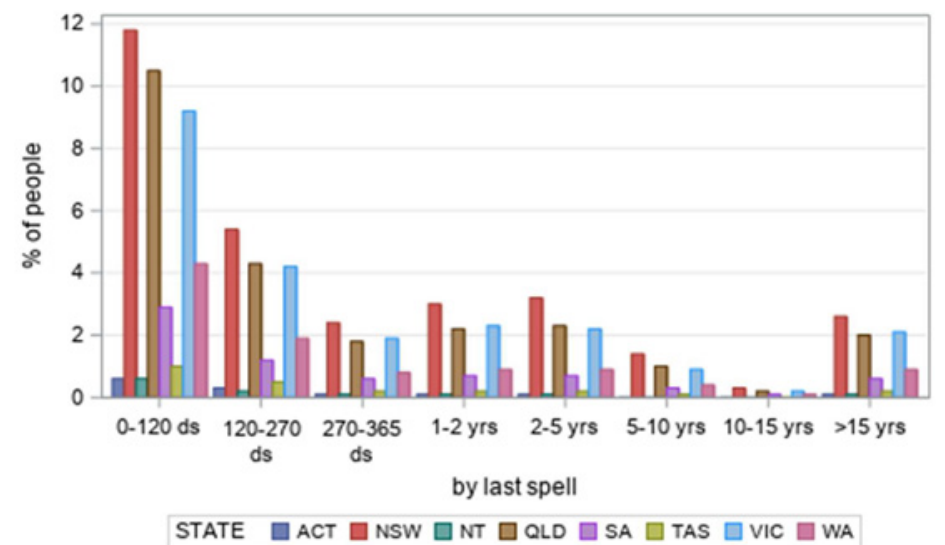

Source: Department of Social Services, DOMINO data (Authors' calculations).

Figure 11: CRA recipients by most common spell across states (Cohort 1)

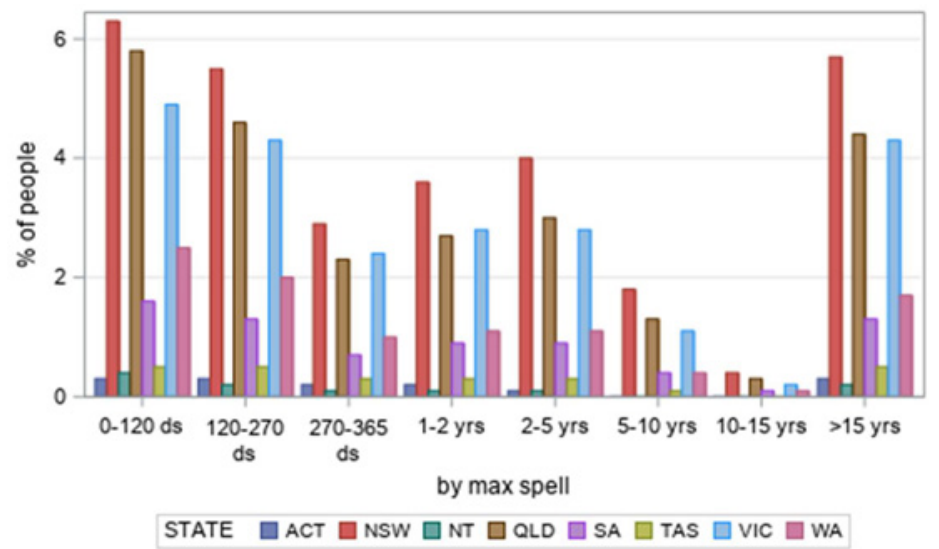

Source: Department of Social Services, DOMINO data (Authors' calculations).

We were unable to explore more disaggregated geographical levels, as the data provided was incomplete for postcode and community code geographical levels. The existing literature indicates the importance of regionality and neighbourhood factors on income variability, therefore it would be helpful to be able to disaggregate the DOMINO data to lower geographical levels. ${ }^{28}$

We also explored housing accommodation types by spell. Figure 12 shows the total number of CRA recipients in different accommodation types as a proportion of the total number of CRA recipients in Cohort 1 , and the proportion of people (in Cohort 1) receiving CRA payments by housing accommodation type for different spell durations. The spell durations, measured in days and years, are based on the most recent (last) CRA payment instance.

28 We are grateful to an anonymous reviewer for this comment. 
The housing accommodation categories are: boarder or lodger (BAL), customer selected for data collection mailout (DAT), exempt (EXE), lives with parents (LWP), joint leasing (LWJ), does not live in shared accommodation (NAS), lives in a residential college or hostel in the academic year (RCO), lives with recipient child only (REC), shares accommodation with home owner $(\mathrm{SHH})$, lives in shared accommodation (SHR), and exempt from sharers rate $(\mathrm{XSH})$.

Not unexpectedly, CRA recipients living in shared accommodation tend to receive their most recent CRA payment for a relatively short spell. The largest group-people not living in shared accommodation-experience a more dispersed range of recent spell periods. Those mainly on short spells of CRA also share accommodation with home owner $(\mathrm{SHH})$, board and lodge (BAL) or live with parents (LWP). Long term last spell CRA recipients tend not to live in shared accommodation (NAS) or are exempt (EXE).

Figure 12: Proportion of CRA recipients by housing accommodation type by last spell (Cohort 1)

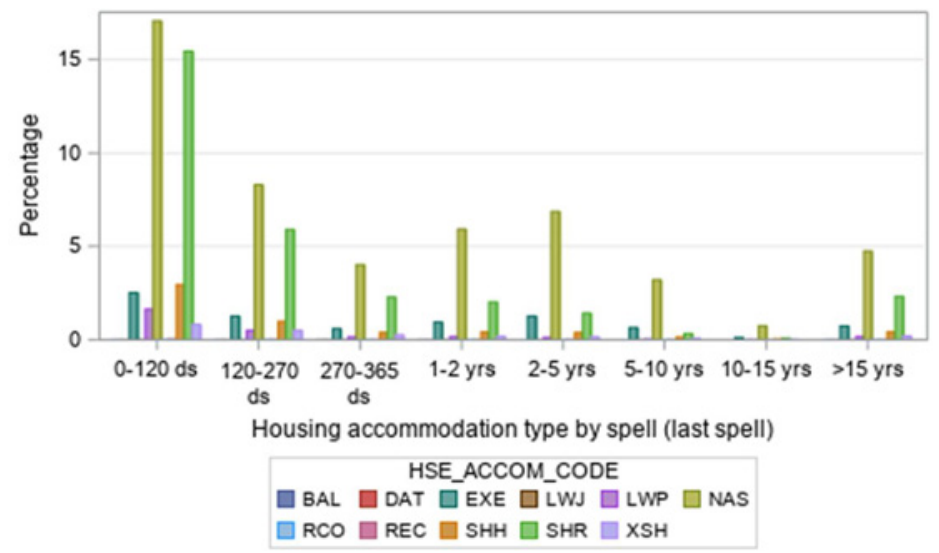

Source: Department of Social Services, DOMINO data (Authors' calculations).

These findings do not differ much if measured based on the most frequent payment spell. Figure 13 shows the proportion of people (in Cohort 1) receiving CRA payments by housing accommodation type by the most common spell duration, measured in days and years, they have experienced. The housing accommodation categories are: boarder or lodger (BAL), customer selected for data collection mailout (DAT), exempt (EXE), lives with parents (LWP), joint leasing (LWJ), does not live in shared accommodation (NAS), lives in a residential college or hostel in the academic year (RCO), lives with recipient child only (REC), shares accommodation with home owner (SHH), lives in shared accommodation (SHR), and exempt from sharers rate (XSH).

Figure 13: Proportion of CRA recipients by housing accommodation type by most common spell (Cohort 1)

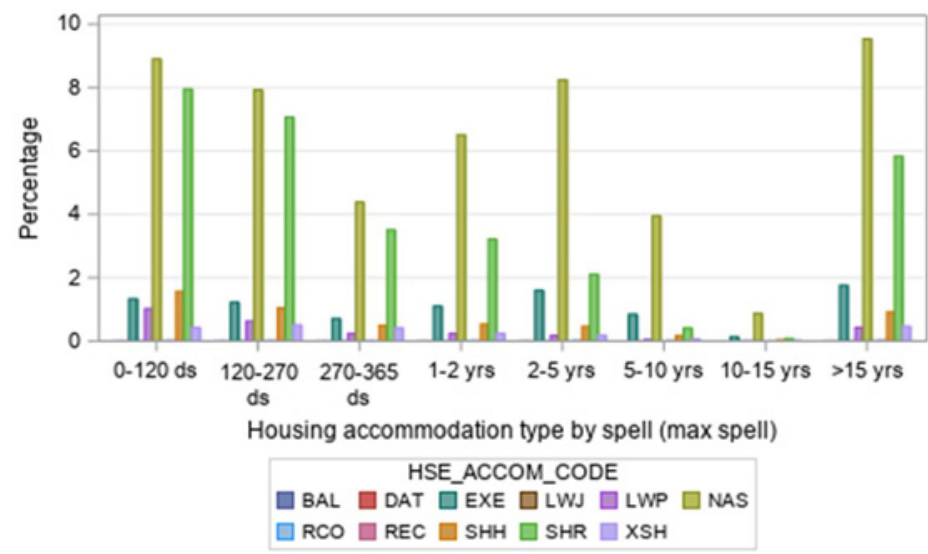

Source: Department of Social Services, DOMINO data (Authors' calculations). 
Rent paid and CRA payments received by Cohort 1

Table 21 below provides descriptive statistics on the weekly rent CRA recipients in Cohort 1 paid. The table reports the mean, standard deviation, minimum, median (50\% of the distribution), and maximum weekly rent paid, as well as the number of weeks rent payments were made. Total sample sizes are also reported in the last column. The first rows show these statistics based on the most recent (last) spell of CRA benefit, while the last rows report the statistics based on the most common (frequent) spell.

Table 21: Most recent and common CRA spells and weekly rent paid

\begin{tabular}{lccccc}
\hline & Mean & STD & Min & Median & Max \\
\hline Most recent spell & & & & & \\
Renting spell (weeks) & 198.4 & 214.6 & $\$ 16.1$ & $3,421.9$ & $3,202,066$ \\
\hline Weekly rent & $\$ 201.7$ & $\$ 120.1$ & $\$ 1$ & $\$ 170$ & $\$, 202,066$ \\
Most common spell & & & 0 & 99 & $3,421.9$ \\
Renting spell (weeks) & 179.5 & 206.5 & $3,285,174$ \\
\hline Weekly rent & $\$ 193.7$ & $\$ 116.3$ & $\$ 1$ & $\$ 160$ & $\$ 9,583$ \\
\hline
\end{tabular}

Source: Department of Social Services, DOMINO data (Authors' calculations).

The median time a CRA recipient is recorded to have lived in a specific accommodation type while receiving CRA payments during their latest spell is slightly over two years (116 weeks). Interestingly, this rental period drops to 99 weeks when their most common CRA spell is identified. Median weekly rent paid is between $\$ 160$ (most common CRA spell) and \$170 (most recent CRA spell).

We then study weekly rent by spells for Cohort 1. Figure 14 shows box-plots for weekly rent paid by CRA recipients in Cohort 1 by spell durations. Box-plot graphs show the distribution of a continuous variable-in this case weekly rent. In particular it shows minimum, maximum values (to comply with data management requirements, we provide minimum and maximum 5\% values), means (indicated by a diamond), medians (lines inside the shaded boxes) as well as first quartiles (bottom 25\% of the distribution) and third quartiles (top 75\% of the distribution) (limits of the shaded boxes). The spell durations, measured in days and years, are based on the most recent (last) CRA payment spell. Figure 15 shows box-plots for weekly rent paid based on the most common CRA payment spell.

Figure 14: Weekly rent distribution by last spell (Cohort 1)

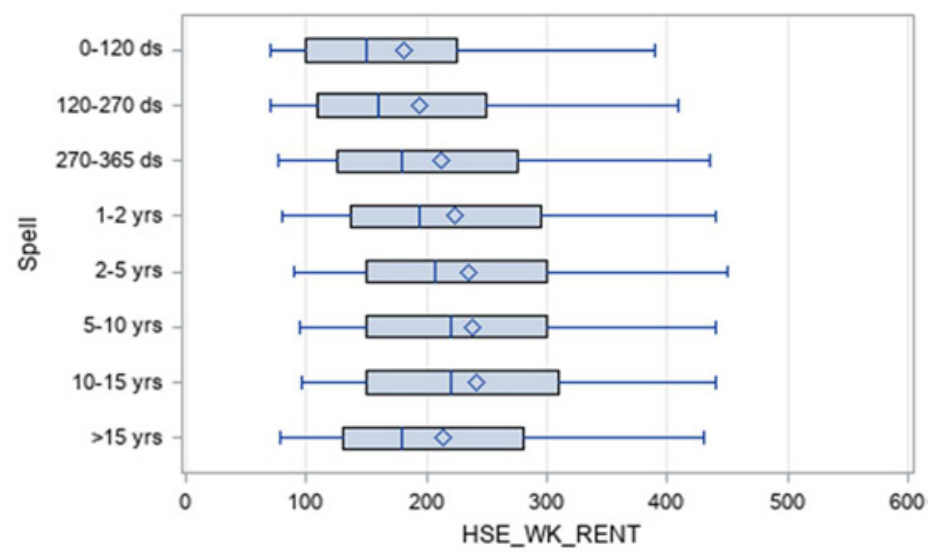

Source: Department of Social Services, DOMINO data, diamond denotes arithmetic mean (Authors' calculations). 
2. Within- and across-year

patterns of CRA receipt:

initial data insights

Figure 15: Weekly rent distribution by most common spell (Cohort 1).

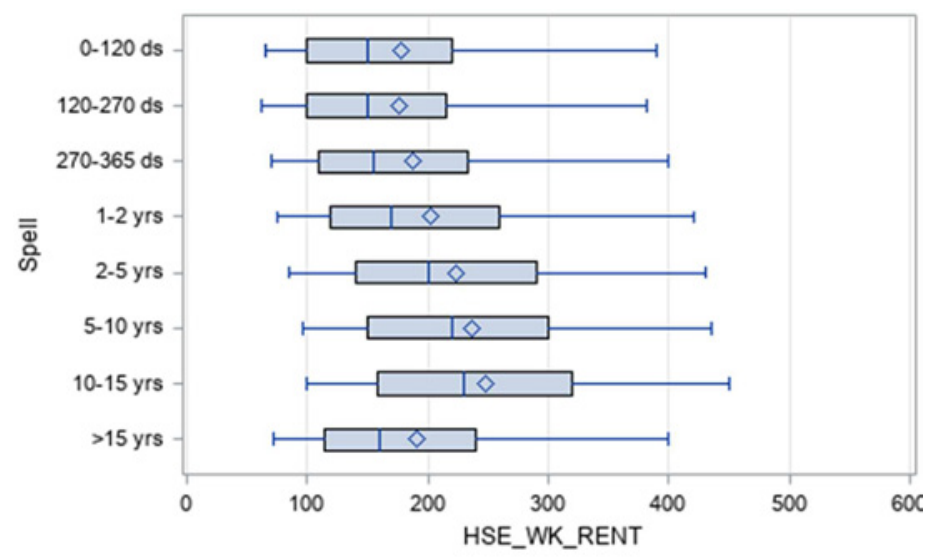

Source: Department of Social Services, DOMINO data, diamond denotes arithmetic mean (Authors' calculations).

Figure 14 shows that most recent CRA recipients on short spells pay lower weekly rent (under \$200) relative to medium term spell recipients. This may be due to the fact that many of them board or lodge, live with parents or live in shared accommodation. Recipients most recently on a long spell (15+ years) also tend to pay lower rent relative to medium term spell recipients. This result is more pronounced when examining most common spell duration in Figure 15. Those on medium to longer spells appear to be paying higher rents, probably due to household sizes and house characteristics, such as number of bedrooms and houses potentially located in convenient neighbourhoods to work and education. That is, this analysis is not controlling for house size or characteristics, as we don't have information at that level.

We then examine CRA payment distributions for different spell lengths for Cohort 1. Shorter term CRA recipients received considerably lower total regular payments. Figures 16 and 17 show daily regular payments.

Figure 16 shows box-plots for daily CRA regular payment received by CRA recipients in Cohort 1 by spell durations. Box-plot graphs show the distribution of a continuous variable-in this case regular daily payment. In particular it shows minimum, maximum values (to comply with data management requirements, we provide minimum and maximum after cutting $5 \%$ of the top and bottom of the distribution), means (indicated by a diamond), medians (lines inside the shaded boxes) as well as first quartiles (bottom 25\% of the distribution) and third quartiles (top $75 \%$ of the distribution) (limits of the shaded boxes). The spell durations, measured in days and years, are based on the most recent (last) CRA payment spell. Figure 17 shows box-plots for daily CRA regular payment received by most common CRA payment spell.

A similar pattern of regular CRA payment rates is found in both figures, with a gradually increasing rate of payment up to long spell recipients (15+ years) who received lower daily CRA rates. One likely explanation for a lower rate of CRA payments for long spell recipients is that the stability of their accommodation is connected to the significantly lower rent these recipients pay (as indicated by Figures 12 and 13). 
2. Within- and across-year

patterns of CRA receipt:

initial data insights

Figure 16: Regular CRA payment amount (daily rate) by last spell (Cohort 1)

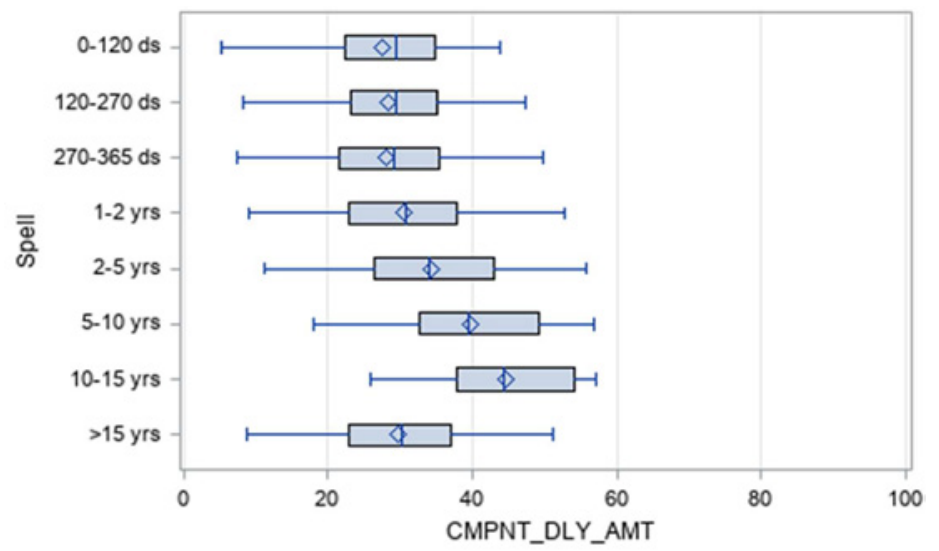

Source: Department of Social Services, DOMINO data, diamond denotes arithmetic mean (Authors' calculations).

Figure 17: Regular CRA payment (daily rate) by most common spell (Cohort 1).

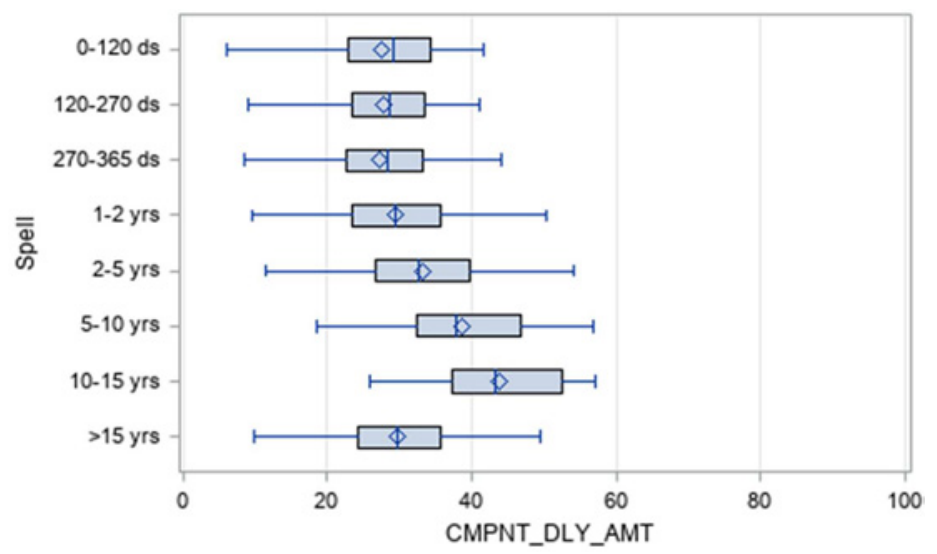

Source: Department of Social Services, DOMINO data, diamond denotes arithmetic mean (Authors' calculations).

CRA recipients also received one-off payments. Figure 18 shows box-plots for total CRA one-off payment received by CRA recipients in Cohort 1 by spell durations. Box-plot graphs show the distribution of a continuous variable-in this case total payment amount. The graph shows minimum, maximum values (to comply with data management requirements, we provide minimum and maximum after cutting $5 \%$ of the top and bottom of the distribution), means (indicated by a diamond), medians (lines inside the shaded boxes) as well as first quartiles (bottom 25\% of the distribution) and third quartiles (top 75\% of the distribution) (limits of the shaded boxes). The spell durations, measured in days and years, are based on the most recent (last) CRA payment spell. Figure 19 shows box-plots for total CRA one-off payment received by most common spell.

Both figures show high average amounts of one-off CRA payments ( $\$ 500$ to over $\$ 2,000$ ) received by recipients with recent and common spells of over 270 days and under 15 years. Whether this is a major concern-given the harmful impacts of income volatility described in the introductory section of this report-can only be answered with further research. 
2. Within- and across-year patterns of CRA receipt:

initial data insights

Figure 18: Total one-off payment amount by last spell (Cohort 1)

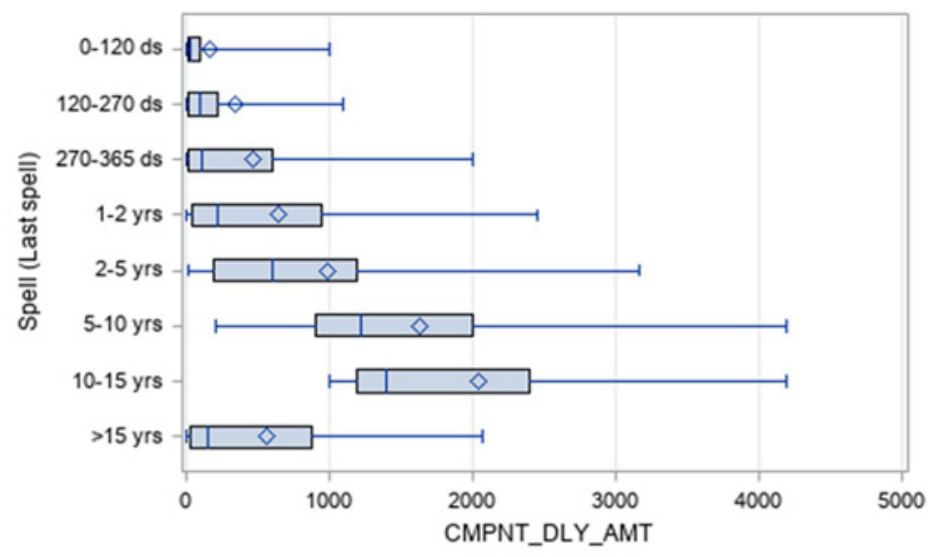

Source: Department of Social Services, DOMINO data, diamond denotes arithmetic mean (Authors' calculations).

Figure 19: Total one-off payment amount by most common spell (Cohort 1)

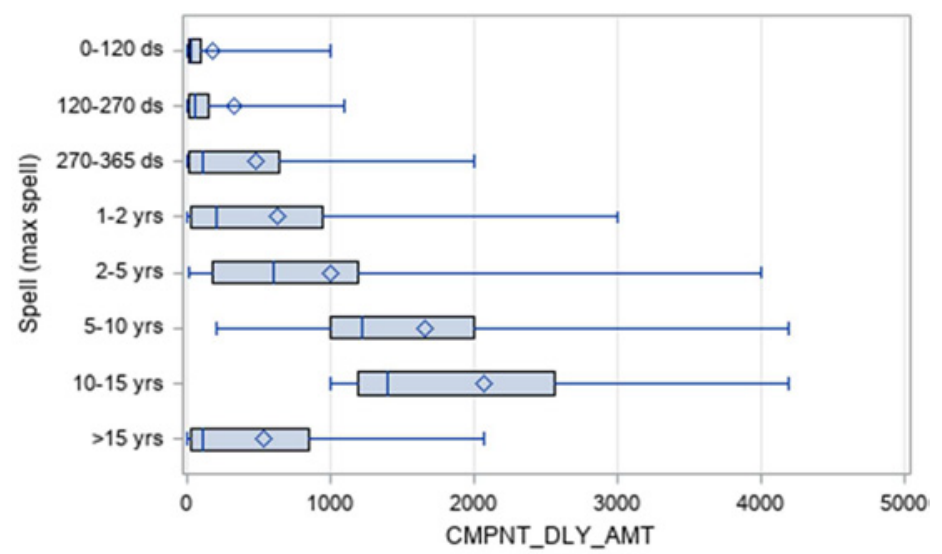

Source: Department of Social Services, DOMINO data, diamond denotes arithmetic mean (Authors' calculations).

\subsubsection{Insight: CRA receipt in 2016}

For housing researchers and policy makers to understand the demand for CRA, measuring the scale and scope of within-year Rent Assistance receipt is a basic empirical prerequisite. Yet the marked difference between stock (point-in-time) and flow data is not always clearly delineated in housing policy analyses.

For example, in a recent research paper titled Vulnerable Private Renters: Evidence and Options, the Productivity Commission states that CRA is 'a targeted payment reaching over 1.3 million recipients in 2016-17 at a cost of over \$4 billion per year (AlHW 2018)' (Productivity Commission 2019: 108).

This is not accurate. The Australian Institute and Health and Welfare report referenced by the Productivity Commission does not support its claim (AIHW 2018). The AlHW made no comment on the number of people who received CRA in the 2016-17 financial year. The Institute drew on DSS stock statistics ${ }^{29}$ to make the more specific and narrow observation that on 30 June 2017 there were 1.34 million income units receiving CRA.

29 See DSS Payment Demographic Data June 2017 https://data.gov.au/dataset/ds-dga-cff2ae8a-55e4-47db-a66d-e177fe0ac6a0/ distribution/dist-dga-0457422b-f338-4dd8-82b7-35a5d97f798d/details?a. 
At first glance, the quarterly stock of CRA recipients may appear to suggest fairly stable numbers. DSS has only published CRA demographic data since March 2017. On 31 March 2017 a similar number of income units $(1,339,398)$ was recorded to be receiving CRA. ${ }^{30}$ An inference could be drawn-as was apparently done by the Productivity Commission - that approximately 1.3 million individuals received CRA in 2016-17.

However, we identified nearly 2 million $(1,967,028)$ income units to be receiving CRA payments for some period of time during 2016. ${ }^{31}$ Further, we found a highly fluid population relied on CRA, with 747,167 income units starting to receive this payment during the year and 505,942 ceasing receipt that year. ${ }^{32}$

30 Department of Social Services, DSS Payment Demographic Data March 2017

31 Using CRA variables list.

32 A preliminary analysis of 2017 data up to October also found higher receipt rates than stock figures appear to suggest. In the first 10 months of this year 1,461,939 income units either started or ended CRA receipt or were currently receiving the payment. 


\section{Discussion and conclusions}

This initial exploration of DOMINO flow data provides new (if provisional) insights into the scale, scope, prevalence and patterns of CRA receipt not possible with stock-based analyses. Two stages comprising five questions informed the direction of the investigation revealing:

- Between January 2000 and October 2017, 11 million Australians were identified to have received a Centrelink payment. This finding offers further compelling evidence that welfare is as much part of mainstream life as health and education.

- Over 5 million individuals received CRA during this period.

- Demand for CRA is far higher than commonly understood. We identified nearly 2 million $(1,967,028)$ income units who received CRA payments during 2016.

- CRA recipients received on average 3.2 instances of CRA payments; half of them receiving 2 instances of CRA payments in their lifetime.

- While the number of people receiving CRA has gradually increased over time, there are fewer new CRA recipients joining each year.

- The most recent CRA benefit spell experienced by a recipient is quite short-51 per cent of recipients most recently received this payment for less than a year. Fewer than one in five (19.7\%) had most recently been receiving CRA for over two years. For Cohort 1, CRA spells last on average 363 days, and 50 per cent of them are shorter than 130 days.

- The most common spell period was somewhat longer. Over a third (37.5\%) of recipients most commonly received CRA for less than a year whilst 32.1 per cent most commonly received this supplement for more than two years.

- 70 per cent of those who received CRA between January 2000 and October 2017 received less than three years total accrued CRA payments.

- There is a significant churn of individuals who receive CRA that is not captured by stock data commonly used in housing policy analyses. We found a highly fluid population relied on CRA during 2016, with 747,167 income units starting to receive this payment and 505,942 ceasing receipt.

- Most CRA recipients appear to have received at least once a one-off irregular CRA payment, suggesting within-year income volatility.

- The average amount of one-off CRA payments across the cohorts was significant ( $\$ 78.50$ to $\$ 100)$. Potentially more significant is the far wider spread of amounts typically paid as one-off payments that may (or may not) be highly disruptive to a household's income stability, with a standard deviation from the average of between $\$ 283.80$ and $\$ 462.10$.

- An analysis of Cohort 1 showed very high average amounts of one-off CRA payments ( $\$ 500$ to over $\$ 2,000)$ received by recipients with recent and common spells of over 270 days and under 15 years. Whether this is a major concern can only be answered with further qualitative and statistical research. 
- A scoping analysis of records found that 54.7 per cent were associated with women, suggesting that women are more likely to receive CRA than men.

- In Cohort 1, men are more likely than women to have (most recently and commonly) received a short spell of CRA (less than 270 days).

- Conversely, in Cohort 1, women are more likely than men to have (most recently and commonly) received longer CRA spells (in all categories of more than 270 days). Cohort 1 income units on Newstart are more likely to be receiving CRA payments for very short periods -48.5 per cent received payments for less than 120 days only.

- Cohort 1 income units on Family Tax Benefit are more likely to be receiving CRA payments for longer periods -57 per cent received payments for between 1 and under 10 years. This finding further emphasises that most longer term CRA recipients are women and that most FTB recipients are women.

- Newstart recipients were far more likely to have most recently (77\%) received a spell of CRA shorter than a year-reflecting the policy design of this payment. In contrast 72.6 per cent of the most recent CRA spells linked to FTB payments were for more than a year-also reflecting the longer term needs of families with dependent children.

- Researchers utilising the DOMINO database experience unique administrative, security, financial and technical challenges (see Appendix 1).

In addressing each of the research questions we found that a deeper understanding of the database's complex variables and values - and their historically- and policy-inscribed relationships - is required for more detailed research. Once these issues are resolved, DOMINO offers a unique and powerful resource for housing and welfare research that moves beyond the initial descriptive statistics presented in this paper. Regressions, time-series analyses and other modelling techniques are likely to yield important findings for a wide range of academic disciplines.

We strongly encourage pursuit of further studies utilising this rich information source. However, we also note that successful investigations will demand significant resources in terms of personnel and labour as well as liberal time-lines, unlike studies typically undertaken in our field. In particular, teams comprising domain experts in welfare, public policy and econometrics/statistics are necessary.

Our main finding is that we have shown that receiving CRA is a more a common experience than is generally thought, and further, that flow data analyses can reveal both the diversity of engagements Australians have with the social security system and their distinctive patterns. 


\section{References}

AHURI (2020) Unpacking the challenges in the rental market during COVID-19, AHURI Brief, Australian Housing and Urban Research Institute, Melbourne, accessed 26 April 2020, https://www.ahuri.edu.au/research/covid-19/renting/ unpacking-the-challenges-in-the-rental-market-during-covid-19.

AlHW (2018) Housing assistance in Australia 2018, Australian Institute of Health and Welfare, Canberra, accessed 2 June 2020, https://www.aihw.gov.au/reports/housing-assistance/housing-assistance-in-australia-2018/contents/ financial-assistance.

Australian Bureau of Statistics (ABS) (2019), Characteristics of Employment, Australia August 2019, cat. no. 6333.0, ABS, Canberra.

Australian Government (2015) Public Data Policy Statement, Australian Government, Canberra, accessed 18 September 2020, https://www.pmc.gov.au/sites/default/files/publications/aust_govt_public_data_policy_statement_1.pdf.

Australian Payroll Association (2019) Payroll Benchmarking Study, Australian Payroll Association Pty Ltd, Sydney, accessed 18 September 2020, https://www.payrollhq.com.au/wp-content/uploads/2019/03/2019. BenchmarkingReport_final.pdf.

Avram, S., Brewer, A., Buck, N., Fisher, P. and Fumagalli, L. (2018) 'Household Income Volatility in the UK, 2009-2016', 35th IARIW General Conference, Copenhagen, Denmark.

Banks, M. and Bowman, D. (2017) Juggling risks. Insurance in households struggling with financial insecurity, Brotherhood of St Laurence, Fitzroy, Victoria, accessed 18 September 2020, http://library.bsl.org.au/jspui/ bitstream/1/10391/1/BanksBowman_Juggling_risks_insurance_2017.pdf.

Banks, M. and Bowman, D. (2019) 'Bad timing: the temporal dimensions of economic insecurity', Critical Sociology, vol. 46, no. 4-5, doi: https://doi.org/10.1177/0896920519883935.

BBC (2020) 'Coronavirus: Greatest test since World War Two, says UN chief', BBC.com, London, accessed 1 April 2020, https://www.bbc.com/news/world-52114829.

Burke, T., Neske, C. and Ralston, L. (2004) Entering rental housing, AHURI Final Report No. 59, Australian Housing and Urban Research Institute Limited, Melbourne, https://www.ahuri.edu.au/research/final-reports/59.

Bartels, C. and Bönke, T. (2013) 'Can Households and Welfare States Mitigate Rising Earnings Instability?', Review of Income and Wealth, vol. 59: 250-282.

Bowman, D. and Banks, M. (2018) Hard times. Australian households and financial insecurity, Brotherhood of St Laurence, Fitzroy, Victoria, accessed 18 September 2020, http://library.bsl.org.au/jspui/bitstream/1/10864/1/ BowmanBanks_Hard_times_2018.pdf.

Campbell, I., Parkinson, S. and Wood, G. (2014) Underemployment and housing insecurity: an empirical analysis of HILDA data, AHURI Final Report No. 230, Australian Housing and Urban Research Institute, Melbourne, http://www.ahuri.edu.au/publications/projects/p30674.

Cigdem-Bayram, M., Ong, R. and Wood, G. (2017) A new look at the channels from housing to employment decisions, AHURI Final Report No. 275, Australian Housing and Urban Research Institute Limited, Melbourne, https://www. ahuri.edu.au/research/final-reports/275, doi: 10.18408/ahuri-5307201.

Daly, M. C. and Valletta, R. G. (2008) 'Cross-National Trends in Earnings Inequality and Instability', Economics Letters, vol. 99: 215-219. 
DSS (2019) DSS Payment Demographic Data, Department of Social Services, Canberra, accessed 10 February 2020, https://data.gov.au/data/dataset/dss-payment-demographic-data.

DSS (2020) DSS Payment Demographic Data, Department of Social Services, Canberra, accessed 3 June 2020, https://data.gov.au/data/dataset/dss-payment-demographic-data.

Dynan, K., Elmendorf, D., and Sichel, D. (2012) ‘The Evolution of Household Income Volatility', The B.E. Journal of Economic Analysis \& Policy, vol. 12, no. 2: 1-42.

Farrell, D. and Greig, F. (2016) Paychecks, Paydays, and the Online Platform Economy: Big Data on Income Volatility, JPMorgan Chase \& Co. Institute, https://papers.ssrn.com/sol3/papers.cfm?abstract_id=2911293.

Feeny, S., Ong, R., Spong, H., and Wood, G. (2012) 'The impact of housing assistance on the employment outcomes of labour market programme participants in Australia', Urban Studies, vol. 49, no. 4: 821-844.

Frederick, T. J., Chwalek, M., Hughes, J., Karabanow, J., and Kidd, S. (2014) 'How stable is stable? Defining and measuring housing stability', Journal of Community Psychology, vol. 42, no. 8: 964-979.

Hacker, J., Huber, G., Nichols, A., Rehm, P., Schlesinger, M., Valletta, R. and Craig, S. (2012) The Economic Security Index: A New Measure for Research and Policy Analysis, Institute for the Study of Labor (IZA), Bonn, Germany, http://ftp.iza.org/dp6946.pdf.

Hannagan, A. and Morduch, J. (2015) Income Gains and Month-to-Month Income Volatility: Household evidence from the US Financial Diaries, US Financial Diaries, New York, http://www.usfinancialdiaries.org/paper-1.

Hardy, B., and Ziliak, J. P. (2014) 'Decomposing trends in income volatility: The "wild ride" at the top and bottom', Economic Inquiry, vol. 52, no. 1: 459-476.

Hill, H. D., Morris, P., Gennetian, L. A., Wolf, S. and Tubbs, C. (2013) 'The Consequences of Income Instability for Children's Well-Being', Child Development Perspectives, vol. 7, no. 2: 85-90, doi: 10.1111/cdep.12018.

Hulse, K. (2002) Demand subsidies for private renters: a comparative review, AHURI Positioning Paper No. 32, Australian Housing and Urban Research Institute, Melbourne https://www.ahuri.edu.au/_data/assets/pdf_file/0020/2873/ AHURI_Positioning_Paper_No32_Demand_subsidies_for_private_renters.pdf.

ILO (2018) Time-related underemployment, International Labour Organisation (ILOSTAT), Geneva, Switzerland https://ilostat.ilo.org/resources/concepts-and-definitions/description-time-related-underemployment/.

Jansen, M. (2004) Income volatility in small and developing economies: export concentration matters, Discussion Paper No. 3, World Trade Organization, Geneva, Switzerland, https://www.wto.org/english/res_e/booksp_e/discussion_ papers3_e.pdf.

Jenkins, S. and Cappellari, L. (2014) 'Earnings and Labour Market Volatility in Britain with a Transatlantic Comparison', Labour Economics, vol. 30, no. C: 201-211.

Lawson, J., Pawson, H., Troy, L., van den Nouwelant, R. and Hamilton, C. (2018) Social housing as infrastructure: an investment pathway, AHURI Final Report No. 306, Australian Housing and Urban Research Institute Limited, Melbourne, http://www.ahuri.edu.au/research/final-reports/306, doi: 10.18408/ahuri-5314301.

Li, J., La, H. A., and Sologon, D. M. (2020) ‘Policy, Demography, and Market Income Volatility: What Shaped Income Distribution and Inequality in Australia Between 2002 and 2016?', The Review of Income and Wealth, https:// onlinelibrary.wiley.com/doi/full/10.1111/roiw.12467.

McKernan, S.-M., Ratcliffe, C., Braga, B. and Kalish, E. (2016) Thriving Residents, Thriving Cities. Family Financial Security Matters for Cities, Urban Institute, Washington, DC, accessed 19 September 2020, http://www.urban.org/sites/default/ files/publication/79776/2000747-Thriving-Residents-Thriving-Cities-Family-Financial-Security-Matters-for-Cities.pdf.

Morduch, J. and Schneider, R. (2016) Mismatch: How Income and Expense Volatility Are Undermining Households, Stanford Social Innovation Review, Stanford University, California, accessed 25 September 2020, https://ssir.org/ articles/entry/mismatch_how_income_and_expense_volatility_are_undermining_households\#.

Morris, P., Hill, H., Gennetian, L., Rodrigues, C. and Wold, S. (2015) Income Volatility in U.S. Households with Children: Another Growing Disparity between the Rich and the Poor?, Institute for Research on Poverty, University of Wisconsin-Madison, Madison, Wisconsin, accessed 17 September 2020, http://www.irp.wisc.edu/publications/dps/ pdfs/dp142915.pdf.

New York Times (2020) 'Why the Global Recession Could Last a Long Time', The New York Times, New York, accessed 26 April 2020, https://www.nytimes.com/2020/04/01/business/economy/coronavirus-recession.html.

Nichols, A. and Rehm, P. (2014) 'Income Risk in 30 Countries', The Review of Income and Wealth, vol. 60, no. S1: S98-S116, doi: 10.1111/roiw.12111. 
Ong, R., Wood, G., Whelan, S., Cigdem, M., Atalay, K. and Dodson, J. (2017) Inquiry into housing policies, labour force participation and economic growth, AHURI Final Report No. 285, Australian Housing and Urban Research Institute Limited, Melbourne, https://www.ahuri.edu.au/research/final-reports/285, doi: 10.18408/ahuri-8107001.

Parkinson, S., Cigdem, M., Ong, R. and Taylor, E. (2013) Wellbeing outcomes of lower income renters: a multi-level analysis of area effects, AHURI Positioning Paper No. 154, Australian Housing and Urban Research Institute Limited, Melbourne, https://www.ahuri.edu.au/research/position-papers/154.

Parkinson, S., James, A. and Liu, E. (2018) Navigating a changing private rental sector: opportunities and challenges for low-income renters, AHURI Final Report No. 302, Australian Housing and Urban Research Institute, Melbourne, http://www.ahuri.edu.au/research/final-reports/302, doi: 10.18408/ahuri-5112301.

Productivity Commission (2017) Introducing competition and informed user choice into Human Services: reforms to Human Services, draft report, Australian Government, Canberra.

Productivity Commission (2019) Vulnerable Private Renters: Evidence and Options, research paper, Australian Government, Canberra.

Randolph, B., and Holloway, D. (2007) Rent assistance and the spatial concentration of low income households in metropolitan Australia, AHURI Final Report No. 101, Australian Housing and Urban Research Institute Limited, Melbourne, https://www.ahuri.edu.au/research/final-reports/101.

RBA (2020) Statement on Monetary Policy - August 2020, Reserve Bank of Australia, Canberra, accessed 17 September 2020, https://www.rba.gov.au/publications/smp/2020/aug/forecasts.html.

Rowley, S., Leishman, C., Baker, E., Bentley, R. and Lester, L. (2017) Modelling housing need in Australia to 2025, AHURI Final Report No. 287, Australian Housing and Urban Research Institute, Melbourne, http://www.ahuri.edu.au/ research/final-reports/287, doi: 10.18408/ahuri-8106901.

Sax Institute (2019) SURE, the Secure Unified Research Environment, Sax Institute, Sydney, www.saxinstitute.org.au/ our-work/sure.

Smith-Ramani, J., Mitchell, D. and McKay, K. (2017) Income Volatility - Why it Destabilises Working Families and How Philanthropy Can Make a Difference, Aspen Institute, Washington, DC, accessed 19 September 2020, http://www.aspenepic.org/wp-content/uploads/2017/12/AFN_2017_Income-Volatility_Final.pdf.

Stone, W., Sharam, A., Wiesel, I., Ralston, L., Markkanen, S. and James, A. (2015) Accessing and sustaining private rental tenancies: critical life events, housing shocks and insurances, AHURI Final Report No. 259, Australian Housing and Urban Research Institute Limited, Melbourne, https://www.ahuri.edu.au/research/final-reports/259.

Stone, W., Parkinson, S., Sharam, A. and Ralston, L. (2016) Housing assistance need and provision in Australia: a household-based policy analysis, AHURI Final Report No. 262, Australian Housing and Urban Research Institute Limited, Melbourne, https://www.ahuri.edu.au/research/final-reports/262.

Tomlinson, D. (2018) Irregular Payments: Assessing the breadth and depth of month to month earnings volatility, Resolution Foundation, London, accessed 19 September 2020, https://www.resolutionfoundation.org/publications/ irregular-payments/.

van den Nouwelant, R., Crommelin, L., Herath, S. and Randolph, B. (2016) Housing affordability, central city economic productivity and the lower income labour market, AHURI Final Report No. 261, Australian Housing and Urban Research Institute Limited, Melbourne, http://www.ahuri.edu.au/research/final-reports/261.

Whelan, S. and Parkinson, S. (2017) Housing tenure, mobility and labour market behaviour, AHURI Final Report No. 280, Australian Housing and Urban Research Institute Limited, Melbourne, https://www.ahuri.edu.au/research/finalreports/280.

Whiteford P. (2017) “"Them" and "us": the enduring power of welfare myths', Inside Story, 10 March 2017, accessed 19 September 2020, https://insidestory.org.au/them-and-us-the-enduring-power-of-welfare-myths/.

Whiteford P. and Heron A. (2018) 'Australia: Providing social protection to non-standard workers with tax financing', in OECD (ed) The Future of Social Protection. What works for non-standard workers? OECD Publishing, Paris: 43-74, accessed 19 September 2020, https://www.oecd.org/els/the-future-of-social-protection-9789264306943-en.htm.

Wilkins, R. (2017) The Household, Income and Labour Dynamics in Australia Survey: Selected Findings from Waves 1 to 15, The Melbourne Institute of Applied Economic and Social Research, The University of Melbourne, Melbourne.

Wood, G., Ong, R. and Cigdem, M. (2015) Factors shaping the dynamics of housing affordability in Australia 2001-11, AHURI Final Report No. 244, Australian Housing and Urban Research Institute Limited, Melbourne, https://www. ahuri.edu.au/research/final-reports/244. 


\section{Appendix 1: Working with the DOMINO database-Insights}

In 2015, the Australian Government released a Public Data Policy Statement that placed new expectations on government agencies and bodies to make high-value data available for use by the public, industry and academia (Australian Government 2015).

Three avenues were set up by DSS to make its data available:

- locating enhanced, publicly accessible data resources on the data.gov.au website

- direct collaborations (e.g. using Priority Investment Approach (PIA) data to develop an actuarial valuation of the Australian income support and social security system with PricewaterhouseCoopers) (DSS 2018)

- allowing independent academic researchers access to PIA and DOMINO data.

To facilitate the third approach, the Australian Institute of Health and Welfare (AIHW) commonly functions as the interface between researchers and the Department. The AlHW manages the data requested by researchers, provides advice on applications, and organises Departmental approval of findings. As part of its academic-focused role, the Institute operates under specific ethical and confidentiality guidelines.

The requested data is not stored at AlHW. Another agency, the Sax Institute, provides approved data to be accessed and analysed through SURE-the Secure Uniform Research Environment. The AIHW also manages the relationship between researchers and this entity. Figure 20 shows the key processes involved in accessing data from the SURE environment when two projects are being undertaken concurrently-reflecting our research team's experience.

Figure 20: Diagram of operational model for researcher accessing SURE for two studies

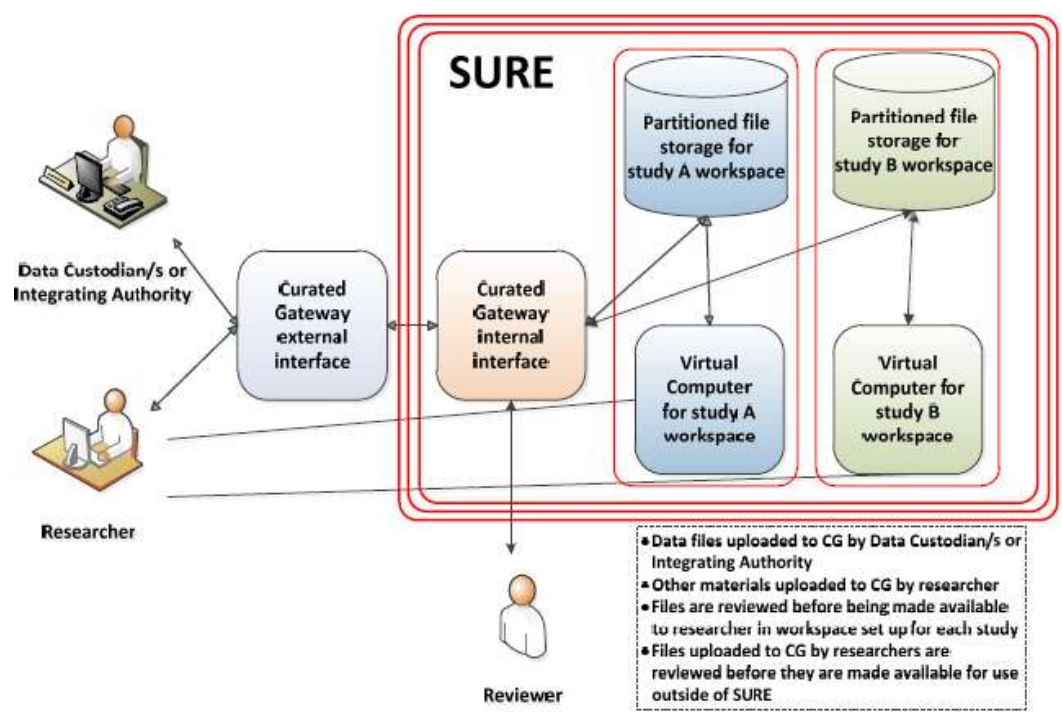

Source: Sax Institute 2019. 
In this diagram, the AlHW acts as the Integrating Authority-releasing requested data to researchers via the Curated Gateway (CG), and checking that findings meet its confidentiality and methodological protocols the researchers upload onto the CG.

For the research team, engaging with these three entities involved attention to compliance, administrative and technical processes that were quite time-consuming and complex. The data was provided through a virtual platform that required confidentiality and security training, and was accessed by a series of passwords and codes. The data folder was shared in a file between the different team members' virtual computers, allowing simultaneous analysis. Discussing analysis in a secure and confidential manner was a challenge, particularly when team members were geographically distant. Documents describing analysis were created within the virtual computer shared access, and had to be passed through the external gateway before they could be shared with all team members.

The virtual environment went through a workspace upgrade in November 2019. Other maintenance interruptions were also scheduled and communicated. Communication about future interruptions from the SURE providers was excellent, however they still affected the work schedule. A couple of research team meetings were postponed, and data analysis was re-scheduled. In addition, the virtual computer was at times slower than expected in opening documents or running codes, which also resulted in a recalibration of project timelines.

Sax Institute charges are detailed in Table 22 below.

Table 22: Sax Institute costs (November 2019)

\begin{tabular}{|c|c|}
\hline Item & Price (ex GST) \\
\hline \multicolumn{2}{|l|}{ Set-up costs } \\
\hline Project setup & $\$ 636.75$ \\
\hline User training (per user) & $\$ 127.00$ \\
\hline \multicolumn{2}{|l|}{ Access costs } \\
\hline Project operations & $\begin{array}{l}\$ 318.38 \\
\text { (annual) }\end{array}$ \\
\hline Virtual machine - 'supervisor' & $\begin{array}{r}\$ 318.38 \\
\text { (per } 3 \text { months) }\end{array}$ \\
\hline Virtual machine - 'standard' & $\begin{array}{r}\$ 636.75 \\
\text { (per } 3 \text { months) }\end{array}$ \\
\hline Virtual machine - 'power' & $\begin{array}{r}\$ 1,273.50 \\
\text { (per } 3 \text { months) }\end{array}$ \\
\hline Per user sharing a virtual machine & $\begin{array}{r}\$ 151.50 \\
\text { (per } 3 \text { months) }\end{array}$ \\
\hline
\end{tabular}

Source: Sax Institute 2019.

Academic research is usually conducted within university ethical guidelines. Data is commonly stored on password protected servers, with hard copy material in locked cabinets. Research team members share and discuss interim findings within these protocols. The unique confidentiality requirements working with DOMINO were highly proscriptive-requiring the team to conduct academic research in a different way to previously experienced.

Overall, this initial evaluation details a wide range of factors that future researchers may need to consider when developing a project proposal. Some of the issues outlined are part of developing the usability of DOMINO for academic research - many of which simply required clarification. However, when planning timelines, researcher and RA resources, and costs, the administrative and technical processes involved in working with three agencies (DSS, AlHW and the Sax Institute) will need careful budgetary consideration. 


\section{Appendix 2: Data requested}

Table 23: DOMINO variables requested

\begin{tabular}{|c|c|}
\hline Member & Variable \\
\hline DOMINO.DET_BEN & BEN_STATUS \\
\hline DOMINO.DET_BEN & BEN_TYPE_CODE \\
\hline DOMINO.DET_BEN & DURN_DAYS \\
\hline DOMINO.DET_BEN & END_RSN \\
\hline DOMINO.DET_BEN & END_RSN_CODE \\
\hline DOMINO.DET_BEN & PERIOD_END_DATE \\
\hline DOMINO.DET_BEN & PERIOD_START_DATE \\
\hline DOMINO.DET_BEN & MAIN_PERSON_ID \\
\hline DOMINO.HH_HSE_DTLS & HSE_ACCOM_CODE \\
\hline DOMINO.HH_HSE_DTLS & HSE_HO_CODE \\
\hline DOMINO.HH_HSE_DTLS & HSE_RENT_TYPE \\
\hline DOMINO.HH_HSE_DTLS & HSE_WK_RENT \\
\hline DOMINO.HH_HSE_DTLS & PERIOD_END_DATE \\
\hline DOMINO.HH_HSE_DTLS & PERIOD_START_DATE \\
\hline DOMINO.HH_HSE_DTLS & MAIN_PERSON_ID \\
\hline DOMINO.LOC_DTLS & CMTY_CODE \\
\hline DOMINO.LOC_DTLS & CTRY_CODE \\
\hline DOMINO.LOC_DTLS & PERIOD_END_DATE \\
\hline DOMINO.LOC_DTLS & PERIOD_START_DATE \\
\hline DOMINO.LOC_DTLS & MAIN_PERSON_ID \\
\hline DOMINO.LOC_DTLS & POSTCODE \\
\hline DOMINO.LOC_DTLS & RMT_IND \\
\hline DOMINO.LOC_DTLS & SA1_MAINCODE_2011 \\
\hline DOMINO.LOC_DTLS & SA2_MAINCODE_2011 \\
\hline DOMINO.LOC_DTLS & STATE \\
\hline DOMINO.MCD_CAREE & ADLT_MED_CODES_GROUP \\
\hline
\end{tabular}




\begin{tabular}{|c|c|}
\hline Member & Variable \\
\hline DOMINO.MCD_CAREE & CHLD_MED_CODE_GROUP \\
\hline DOMINO.MCD_CAREE & PERIOD_END_DATE \\
\hline DOMINO.MCD_CAREE & PERIOD_START_DATE \\
\hline DOMINO.MCD_CAREE & MAIN_PERSON_ID \\
\hline DOMINO.MCD_CAREE & TERM_ILL \\
\hline DOMINO.MCD_DTLS & MED_SCNDRY_GROUP \\
\hline DOMINO.MCD_DTLS & IMPRMT_RATE \\
\hline DOMINO.MCD_DTLS & INCAP_END \\
\hline DOMINO.MCD_DTLS & INCAP_EXEMPT \\
\hline DOMINO.MCD_DTLS & INCAP_START \\
\hline DOMINO.MCD_DTLS & INCAP_WK_WRK_HRS \\
\hline DOMINO.MCD_DTLS & MED_PRMY \\
\hline DOMINO.MCD_DTLS & MED_SCNDRY_PERM \\
\hline DOMINO.MCD_DTLS & PERIOD_END_DATE \\
\hline DOMINO.MCD_DTLS & PERIOD_START_DATE \\
\hline DOMINO.MCD_DTLS & MAIN_PERSON_ID \\
\hline DOMINO.PYH_ONEOFF & BEN_TYPE \\
\hline DOMINO.PYH_ONEOFF & CMPNT_DLY_AMT \\
\hline DOMINO.PYH_ONEOFF & CMPNT_ID \\
\hline DOMINO.PYH_ONEOFF & CMPNT_TYPE \\
\hline DOMINO.PYH_ONEOFF & PERIOD_END_DATE \\
\hline DOMINO.PYH_ONEOFF & PERIOD_START_DATE \\
\hline DOMINO.PYH_ONEOFF & MAIN_PERSON_ID \\
\hline DOMINO.PYH_REGULAR & BEN_TYPE \\
\hline DOMINO.PYH_REGULAR & CMPNT_DLY_AMT \\
\hline DOMINO.PYH_REGULAR & CMPNT_ID \\
\hline DOMINO.PYH_REGULAR & CMPNT_TYPE \\
\hline DOMINO.PYH_REGULAR & PERIOD_END_DATE \\
\hline DOMINO.PYH_REGULAR & PERIOD_START_DATE \\
\hline DOMINO.PYH_REGULAR & MAIN_PERSON_ID \\
\hline DOMINO.PYH_THIRD_PARTY & BEN_TYPE \\
\hline DOMINO.PYH_THIRD_PARTY & CMPNT_DLY_AMT \\
\hline DOMINO.PYH_THIRD_PARTY & CMPNT_ID \\
\hline DOMINO.PYH_THIRD_PARTY & CMPNT_TYPE \\
\hline DOMINO.PYH_THIRD_PARTY & PERIOD_END_DATE \\
\hline DOMINO.PYH_THIRD_PARTY & PERIOD_START_DATE \\
\hline
\end{tabular}




\begin{tabular}{ll}
\hline Member & Variable \\
\hline DOMINO.PYH_THIRD_PARTY & MAIN_PERSON_ID \\
\hline DOMINO.RLT_DTLS & PERIOD_END_DATE \\
\hline DOMINO.RLT_DTLS & PERIOD_START_DATE \\
\hline DOMINO.RLT_DTLS & MAIN_PERSON_ID \\
\hline DOMINO.RLT_DTLS & REL_CODE \\
\hline DOMINO.RLT_DTLS & REL_ID \\
\hline DOMINO.STT_PIT & AGE \\
\hline DOMINO.STT_PIT & BIRTH_CTRY_CODE \\
\hline DOMINO.STT_PIT & DATE_OF_BIRTH \\
\hline DOMINO.STT_PIT & DATE_OF_DEATH \\
\hline DOMINO.STT_PIT & GENDER \\
\hline DOMINO.STT_PIT & INDIG_CODE \\
\hline DOMINO.STT_PIT & PEN_BLIND_START_DATE \\
\hline DOMINO.STT_PIT & MAIN_PERSON_ID
\end{tabular}




\section{AHURi}

Australian Housing and Urban Research Institute Level 12, 460 Bourke Street

Melbourne VIC 3000

\section{Australia}

+61396602300

information@ahuri.edu.au

ahuri.edu.au

(2) twitter.com/AHURI_Research

f facebook.com/AHURI.AUS

in Australian Housing and Urban Research Institute 